\title{
The $\mathrm{CD} 14^{+} \mathrm{CD} 16^{+}$Inflammatory Monocyte Subset Displays Increased Mitochondrial Activity and Effector Function During Acute Plasmodium vivax Malaria
}

\author{
Lis R. V. Antonelli ${ }^{1 *}$, Fabiana M. S. Leoratti ${ }^{1}$, Pedro A. C. Costa ${ }^{1}$, Bruno C. Rocha ${ }^{1,2}$, Suelen Q. Diniz ${ }^{1}$, \\ Mauro S. Tada ${ }^{3}$, Dhelio B. Pereira ${ }^{3}$, Andrea Teixeira-Carvalho ${ }^{4}$, Douglas T. Golenbock ${ }^{5}$, \\ Ricardo Gonçalves ${ }^{6}$, Ricardo T. Gazzinelli ${ }^{1,2}$
}

1 Laboratório de Immunopatologia, Centro de Pesquisas René Rachou, Fundação Oswaldo Cruz, Belo Horizonte, Minas Gerais, Brazil, 2 Departamento de Bioquímica e Imunologia, Universidade Federal de Minas Gerais, Belo Horizonte, Minas Gerais, Brazil, 3 Centro de Pesquisas em Medicina Tropical de Rondônia, Porto Velho, Rondônia, Brazil, 4 Laboratório de Biomarcadores de Diagnóstico e Monitoração, Centro de Pesquisas René Rachou, Fundação Oswaldo Cruz, Belo Horizonte, Minas Gerais, Brazil, 5 Division of Infectious Diseases and Immunology, University of Massachusetts Medical School, Worcester, Massachusetts, United States of America, 6 Departamento de Patologia Geral, Universidade Federal de Minas Gerais, Belo Horizonte, Minas Gerais, Brazil

\begin{abstract}
Infection with Plasmodium vivax results in strong activation of monocytes, which are important components of both the systemic inflammatory response and parasite control. The overall goal of this study was to define the role of monocytes during $P$. vivax malaria. Here, we demonstrate that $P$. vivax-infected patients display significant increase in circulating monocytes, which were defined as $\mathrm{CD} 14^{+} \mathrm{CD} 16^{-}$(classical), $\mathrm{CD} 14^{+} \mathrm{CD} 16^{+}$(inflammatory), and $\mathrm{CD} 14^{\mathrm{lo}} \mathrm{CD} 16^{+}$(patrolling) cells. While the classical and inflammatory monocytes were found to be the primary source of pro-inflammatory cytokines, the $\mathrm{CD}_{16}{ }^{+}$cells, in particular the $\mathrm{CD} 14^{+} \mathrm{CD} 16^{+}$monocytes, expressed the highest levels of activation markers, which included chemokine receptors and adhesion molecules. Morphologically, CD14 ${ }^{+}$were distinguished from CD $14^{\text {lo }}$ monocytes by displaying larger and more active mitochondria. $C D 14^{+} \mathrm{CD} 16^{+}$monocytes were more efficient in phagocytizing $P$. vivaxinfected reticulocytes, which induced them to produce high levels of intracellular TNF- $\alpha$ and reactive oxygen species. Importantly, antibodies specific for ICAM-1, PECAM-1 or LFA-1 efficiently blocked the phagocytosis of infected reticulocytes by monocytes. Hence, our results provide key information on the mechanism by which CD $14^{+} \mathrm{CD} 16^{+}$cells control parasite burden, supporting the hypothesis that they play a role in resistance to $P$. vivax infection.
\end{abstract}

Citation: Antonelli LRV, Leoratti FMS, Costa PAC, Rocha BC, Diniz SQ, et al. (2014) The CD14 ${ }^{+}$CD $16^{+}$Inflammatory Monocyte Subset Displays Increased Mitochondrial Activity and Effector Function During Acute Plasmodium vivax Malaria. PLoS Pathog 10(9): e1004393. doi:10.1371/journal.ppat.1004393

Editor: Mary M. Stevenson, McGill University, Canada

Received December 3, 2013; Accepted August 11, 2014; Published September 18, 2014

Copyright: (c) 2014 Antonelli et al. This is an open-access article distributed under the terms of the Creative Commons Attribution License, which permits unrestricted use, distribution, and reproduction in any medium, provided the original author and source are credited.

Funding: We acknowledge the Program for Technological Development in Tools for Health-PDTIS-FIOCRUZ for the use of its facilities. This work was supported by FAPEMIG (01/2011), CNPq (14/2011), PAPES VI, FIOCRUZ, the US National Institutes of Health (AI079293), by National Institute of Science and Technology for Vaccines (CNPq-573547/2008-4/FAPEMIG/MS-CBB-APO 00077-09) and Rede Malária (CNPq-555646/2009-2/FAPEMIG/MS-CBB-APO-01153-10). RTG is a recipient of a Visiting Professor Fellowship from CAPES and the David Rockefeller Center for Latin American Studies at the Harvard School of Public Health. LRVA, ATC and RTG are CNPq fellows (PQ) and DTG is a FAPEMIG fellow. The funders had no role in study design, data collection and analysis, decision to publish, or preparation of the manuscript.

Competing Interests: The authors have declared that no competing interests exist.

* Email: lisantonelli@cpqrr.fiocruz.br

\section{Introduction}

Plasmodium vivax is the most widely distributed malaria parasite and responsible for approximately 70-80 million cases, annually. In addition, $P$. vivax is responsible for the majority of malaria cases and represents a significant impediment to social and economic development in Latin America and Asia [1]. Both innate and acquired immunity are thought to play critical role in host resistance to infection and pathogenesis of malaria [2,3]. However, the mechanisms by which the innate immune response mediate resistance to Plasmodium infection or promote a deleterious systemic inflammation associated with malaria sepsis are poorly understood [2]. This is particularly true in the case of $P$. vivax malaria [4].

The blood is the main tissue affected during $P$. vivax malaria since sequestration is not a central event in this infection. When parasitized reticulocytes rupture in the blood stream, parasite components are sensed by the innate immune receptors and activate monocytes [5]. The innate immune system recognizes Plasmodium sp. through different pattern-recognition receptors expressed by monocytes and initiates a broad spectrum of defense mechanisms $[6,7,8,9,10]$. Importantly, the same immune mediators involved in host resistance, such as pro-inflammatory cytokines are also thought to mediate pathology during acute malaria episodes $[8,11,12]$. However, the full spectrum of monocyte subsets and the specific functions of each monocyte population during malaria have not been defined.

Besides supplying peripheral tissues with macrophage and dendritic cell (DC) precursors, monocytes contribute directly to immune defense against microbial pathogens [13,14,15]. Monocytes were initially identified by their expression of large amounts of CD14 [16,17]. However, recent studies have revealed that monocytes in human peripheral blood are heterogeneous and can be divided into three distinct subsets described based on their 


\section{Author Summary}

Malaria, caused by a protozoa parasite, Plasmodium, affects more than 200 million people per year. The infection triggers an acute febrile illness, the paroxysms, occurring every 48 or 72 hours depending on the species. Plasmodium vivax, in most cases, does not cause severe malaria, but it is the most geographically widespread parasite responsible for human disease and causes substantial costs to individuals and governments. Once the parasite reaches the blood stream, they infect reticulocytes that can be destroyed by phagocytes. Our goal was to assess the importance of monocyte subsets during malaria. We found that $P$. vivax infection causes an increase in frequency of circulating monocytes, which were defined as classical, inflammatory, and patrolling, based on the expression of membrane molecules. Classical and inflammatory monocytes produced higher levels of pro-inflammatory cytokines and were distinguished from patrolling monocytes by displaying larger and more active mitochondria. Importantly, inflammatory monocytes were more efficient phagocytes; produced high levels of intracellular reactive oxygen species and TNF and consequently control better Plasmodium vivax infection. Hence, our results support the hypothesis that $\mathrm{CD} 14^{+} \mathrm{CD} 16^{+}$monocytes display effector functions involved in parasite control during malaria.

expression of phenotypic markers. These cells are referred to as, classical $\left(\mathrm{CD}_{1} 4^{+} \mathrm{CD} 16^{-}\right.$cells), inflammatory or intermediate $\left(\mathrm{CD} 14^{+} \mathrm{CD} 16^{+}\right)$and patrolling $\left(\mathrm{CD} 14^{\mathrm{lo}} \mathrm{CD} 16^{+}\right)$monocytes $[18,19]$. Given the importance of monocytes as a major source of pro-inflammatory cytokines and potential effector cells during malaria, in this study, we have attempted to define the role of the various monocyte subsets during $P$. vivax infection. To address this question, we phenotypically and functionally characterized the classical, inflammatory, and patrolling monocytes present in the peripheral blood from patients experiencing acute malaria episodes.

We demonstrate that the frequency of circulating monocytes is elevated during acute infection with $P$. vivax and that the classical and inflammatory monocyte subsets are the primary source of proinflammatory cytokines. Importantly, we found that $\mathrm{CD}_{1} 6^{+}$cells, and in particular the $\mathrm{CD} 14^{+} \mathrm{CD} 16^{+} \mathrm{LFA}-1^{\text {high }}$ ICAM- $1{ }^{\text {high }} \mathrm{PE}-$ CAM- $1^{\text {high }}$ monocytes display augmented effector functions such as phagocytosis and intracellular reactive oxygen species production and are thus likely to be an important cell subset controlling parasitemia, and mediating host resistance to $P$. vivax infection.

\section{Methods}

\section{Patients}

A total of $35 P$. vivax-infected patients with uncomplicated malaria were enrolled in this study at Centro de Pesquisa de Medicina Tropical de Rondônia (CEPEM) in Porto Velho, Rondônia, a malaria endemic area in the Amazon region of Brazil. According to the World Health Organization, uncomplicated malaria is a symptomatic infection with malaria parasitemia without signs of severity and/or evidence of vital organ dysfunction. Up to $100 \mathrm{ml}$ of peripheral blood was collected immediately after confirmation of $P$. vivax infection by thick blood smear film and again 30-45 days after chemotherapy $(\mathrm{n}=35$,

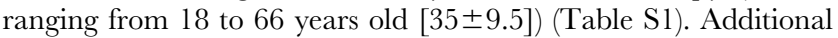
$36 P$. vivax-infected patients were enrolled for reticulocyte analysis: percentage: mean: 1.383, SD: 0.655; median: 1.150, IQR: 0.925-1.650; absolute numbers: mean: 51,779, SD: 18,390; median: 48,100, IQR: 38,970-59,520. Patients were treated for 3 days with chloroquine followed by 7 days with primaquine according to the Brazilian Ministry of Health. P. vivax infection and parasitological cure were confirmed by thick blood smear film and polymerase chain reaction (PCR) [20]. Identification of the three species of human malaria parasites was done by nested PCR that targets variant sequences in the small subunit rRNA gene. The clinical manifestations of acute malaria were fever, myalgia, chills, arthralgia, nausea, vomiting or diarrhea. Peripheral blood was also collected from 15 healthy donors (HD) ranging from 21 to 56 years old [32 \pm 8 ] living in Porto Velho and negative for $P$. vivax infection.

\section{Ethics statement}

These studies were performed under protocols reviewed and approved by the Ethical Committees on Human Experimentation from Centro de Pesquisa em Medicina Tropical de Rondônia (CEP-CEPEM 095/2009) and Centro de Pesquisas René Rachou, Fundação Oswaldo Cruz (CEP-GPqRR 2004), the National Ethical Committee (CONEP 15652) from Ministry of Health, Brazil, as well as by the Institutional Review Board from the University of Massachusetts Medical school. Only adults, 18 years old, were enrolled in the study. All patients enrolled in this study provided written informed consent.

\section{Cellular immunophenotyping}

Peripheral blood mononuclear cells (PBMC) were prepared from heparinized venous blood of adult volunteers by FicollHypaque density gradient centrifugation (GE Healthcare Life Sciences). Cells were stained for surface molecules for 15 minutes at room temperature. Subsequently, PBMC were washed with FACS buffer (PBS and 2\%FBS), and fixed and permeabilized according to the manufacture's instruction (Cytofix/Cytoperm, BD Biosciences). Cells were then stained for the intracellular antigens. Cells were finally suspended and maintained in $200 \mu \mathrm{l}$ of PBS 2\% paraformaldehyde (Sigma Aldrich). At least 100,000gated events were acquired for analysis using FACSCan upgraded with a second laser (5 colors) with Cellquest Pro and Rainbow from Cytek or LSR II with Diva (both from BD Biosciences). The antibody panels included the following: anti-CD31 (clone WM59)FITC, anti-CD1 la (LFA-1) (clone HI111)-FITC, anti-HLA-DR (clone LN3)-PE, anti-CD14 (clone 61D3)-APC, anti-CD62L (clone DREG56)-APG, anti-HLA-DR (clone LN3)-efluor 780, antiCX3CR1 (clone 2A9-1)-biotin, anti-CD106 (VCAM-1) (clone STA)-biotin and streptavidin-PE, all purchased from eBioscience; anti-CD54 (ICAM-1) (clone HA58)-PE, anti-TNF- $\alpha$ (clone MAb11)-PE, anti-IL-6 (clone MQ2-13A5)-PE, anti-CD197 (CGR7) (clone 3D12)-PECy7 and anti-GD16 (clone 3G8)PercPGy5.5, purchased from BD Biosciences; anti-GCR2 (clone 48607)-PE, purchased from R\&D Systems. Data were analyzed using FlowJo Version 9.3.2 (TreeStar). A forward scatter height (FSC-H) and a side scatter height (SSC-H) gate were used to initially remove debris and to capture leucocytes. CD14 versus SSC-H gate was then used to select monocytes. An additional HLA-DR versus CD16 gate was performed to exclude possible contamination by neutrophils (CD16 ${ }^{+}$HLA-DR ${ }^{-}$). A more detailed analysis of monocyte subpopulations was done based on CD14 and CD16 expression and here designated as: classical monocytes $\left(\mathrm{CD}_{1} 4^{+} \mathrm{CD} 16^{-}\right)$, inflammatory monocytes $\left(\mathrm{CD} 14^{+} \mathrm{CD} 16^{+}\right)$, and patrolling monocytes $\left(\mathrm{CD} 14^{\mathrm{l}} \mathrm{CD}^{+} 6^{+}\right)$. The activation/cell presentation molecule, HLA-DR; the cellular adhesion molecules, VCAM-1, ICAM-1, PECAM-1, and LFA-1; the chemokine receptors, CGR2, GX3CR1 and CGR7; and the cytokine TNF- $\alpha$ was analyzed within $\mathrm{CD} 14^{+}$cells and also within 
each monocyte subpopulation. Data is shown in frequencies or mean fluorescence intensity (MFI). In the latter, when graphs are overlaid, the y-axis is left on automatic scaling and the axis represents \% of Maximum. This normalization is used because different numbers of events is collected for the monocyte subsets analyzed and allow us to focus on the important and relevant variations between the levels of expression of different markers on the $\mathrm{x}$-axis.

\section{Cytokine measurements}

IL-6, IL-8 and IL-10 were measured in cryopreserved plasma using the Cytometric Bead Array kit (CBA, BD Biosciences Pharmingen) as recommended by the manufacturer. The concentration of cytokines in each sample was calculated using the BD FCAP Array Software v 1.0.1 (BD Biosciences).

\section{$P$. vivax-parasitized reticulocytes enrichment and staining}

The red blood cells pellet from the Ficoll-Hypaque (GE Healthcare Life Sciences) density gradient centrifugation was harvested and washed three times and then resuspended in RPMI 1640 medium (Sigma Aldrich) to a final hematocrit of 10\%. Five milliliters of this suspension was overlaid on a $5 \mathrm{~mL} 45 \%$ Percoll solution in a $15 \mathrm{~mL}$ tube. After centrifugation, floating mature $\mathrm{Pv}$ reticulocytes ( $\mathrm{Pv}$-Ret) were collected and resuspended in RPMI 1640 [21,22]. The enrichment of Pv-Ret was assessed by optic microscopy and a purity of $95 \%$ was obtained. Where indicated, enriched Pv-Ret were stained with $1 \mu \mathrm{M}$ carboxyfluorescein succinimidyl ester (CFSE) at $1 \times 10^{6}$ cells $/ \mathrm{mL}$ for 8 minutes at room temperature before phagocytosis assays (Molecular ProbesInvitrogen). After stained Pv-Ret were washed three times in RPMI and $10 \%$ FBS.

\section{Expression of NADPH subunits by monocyte subsets}

P47phox and p67phox expression was assessed by incubating PBMC in suspension at $37^{\circ} \mathrm{C}$ in complete RPMI 1640 supplemented with $2 \mu \mathrm{M}$ glutamine, $10 \mathrm{mM}$ HEPES and $50 \mu \mathrm{M} 2-\mathrm{ME}$ for 3 hours in medium alone and with $P$. vivax-Ret $(0.5$ Pv-Ret/ PBMC) in the presence of $10 \%$ immune serum. PBMC were then washed with FACS buffer, stained for surface molecules for 15 minutes at room temperature, fixed and permeabilized according to the manufacture's instruction (Cytofix/Cytoperm, BD Biosciences).. Cells were then stained for the intracellular antigens (p47phox and p67phox) for 20 minutes, following additional 20 minutes incubation with anti-IgG1. After staining, plates were kept on ice for 15 minutes and cells were harvested with ice-cold PBS, $2.5 \mathrm{mM}$ EDTA and maintained in $200 \mu \mathrm{l}$ of PBS 2\% paraformaldehyde. At least 100,000-gated events were acquired for analysis using a LSRFortessa (BD Biosciences). The antibody panels included the following: anti-CD16 (clone 3G8)Alexa Fluor 700, anti-HLA-DR (Tu39)-FITC, anti-CD14 (clone M5E2)-APG, purified anti-phox47 (1/p47Phox) and anti-phox67 (D-6), and anti-IgG1 (A851)-PE. The MFI of each monocyte subpopulation expressing the NADPH subunits was determined by flow cytometry. Data were analyzed using FlowJo Version $\mathrm{X}$ 10.0.7.

\section{Phagocytosis}

Phagocytosis was assessed by incubating PBMC in suspension using 96-wells polystyrene plates at $37^{\circ} \mathrm{C}$ in complete RPMI 1640 supplemented with $10 \%$ heat-inactivated FCS, $2 \mu \mathrm{M}$ glutamine, $10 \mathrm{mM}$ HEPES, and $50 \mu \mathrm{M}$ 2-ME for 1,4 and 12 hours with $P$. vivax-Ret previously stained with CFSE (0.5 Pv-Ret/PBMC) in the absence of immune serum and in the presence of serum or inactivated serum. In some experiments monoclonal antiCD1la (1 mg/mL) (clone G43-25B, BD), anti-CD31 (0.5 mg/ $\mathrm{mL}$ ) (clone WM59), anti-CD36 (0.5 mg/mL) (clone CB38) and anti-CD54 $(1 \mathrm{mg} / \mathrm{mL})$ (clone HA58) blocking antibodies were added in the cultures 30 minutes before the addition of $P$. vivax-Ret. After staining, plates were kept on ice for 15 minutes and cells were harvested with ice-cold PBS containing $2.5 \mathrm{mM}$ EDTA. The frequencies of total monocytes and each monocyte subpopulation positive for CFSE were determined by flow cytometry and data were analyzed using FlowJo Version 9.3.2 (TreeStar).

\section{ROS detection}

To detect ROS production at the single cell level, the Image-iT LIVE Green Reactive Oxygen Species Detection kit (Invitrogen) was used following the manufacturer's instructions. Briefly, PBMC were washed twice with PBS and incubated in medium alone or with Pv-Ret (0.5 Pv-Ret/PBMC) or phorbol 12-myristate 13acetate (PMA, $10 \mathrm{ng} / \mathrm{mL}$ ) and ionomycin $(500 \mathrm{ng} / \mathrm{mL})$. Prewarmed $25 \mu \mathrm{M}$ 5-(and-6)-carboxy-2', 7'-dichlorodihydrofluorescein diacetate (carboxy- $\mathrm{H}_{2}$ DCFDA) was added to the cells for 3 hours at $37^{\circ} \mathrm{C}$. Mitochondrial ROS was assessed by MitoSox red mitochondrial superoxide indicator (Invitrogen) following the manufacturer's instructions. Briefly, PBMC were washed twice with HBSS and incubated in medium alone or with $\mathrm{Pv}$-Ret $(0.5$ Pv-Ret/PBMC) or PMA (10 ng/mL) and ionomycin (500 ng/mL) and $10 \mu \mathrm{m}$ MitoSox. After 30 minutes incubation, monoclonal antibodies against CD14 and CD16 were added to cell cultures to allow monocyte subpopulations analysis. Cell suspension was washed after additional 30 minutes incubation with HBSS at $37^{\circ} \mathrm{C}$. Plates were kept on ice for 15 minutes and cells were harvested with ice-cold PBS containing $2.5 \mathrm{mM}$ EDTA. Cells were acquired by flow cytometry and data were analyzed using FlowJo Version 9.3.2.

\section{Purification of monocyte subpopulations}

After PBMC preparation $\mathrm{CD} 14^{+} \mathrm{CD} 16^{-}, \mathrm{CD} 14^{+} \mathrm{CD} 16^{+}$and $\mathrm{CD} 14^{\mathrm{lo}} \mathrm{CD} 16^{+}$monocytes from $\mathrm{HD}$ and $P$. vivax-infected patients were sorted with a FACSAria II cell sorter (BD Biosciences), using the combination of antibodies described above. $\mathrm{CD} 14^{+} \mathrm{CD} 16^{-}$, $\mathrm{CD} 14^{+} \mathrm{CD} 16^{+}$and $\mathrm{CD} 14^{\mathrm{lo}} \mathrm{CD} 16^{+}$monocytes were then collected and fixed with $2.5 \%$ buffered glutaraldehyde solution, $0.1 \mathrm{M}$, for electron microscopy or with RLT buffer (QIAGEN) supplemented with $\beta$-mercaptoethanol for mRNA detection and nanostring analysis as described below.

\section{Electron microscopy}

After FACS-sorting, cells were prepared as previously described [23,24]. Briefly, cells were fixed in $2.5 \%$ buffered glutaraldehyde solution, $0.1 \mathrm{M}, \mathrm{pH} 7.2,6 \mathrm{~h}, 8^{\circ} \mathrm{C}$. Cells were then washed with the same buffer. The pellets were included in phosphate buffer, $4 \%$ agarose and left overnight at $4^{\circ} \mathrm{C}$. Next, the cells were fixed in a mixture of $1 \%$ osmium tetroxide and $1.5 \%(\mathrm{w} / \mathrm{v})$ potassium ferrocyanide, dehydrated in a graded series of ethanol solutions, infiltrated, and embedded in Araldite 502 (Electron Microscopy Sciences, Hatfield, PA, USA). After polymerization, thin sections were obtained using a diamond knife on a Sorvall MT-2B ultramicrotome (Dupont, Wilmington, DE, USA) and mounted on uncoated 200-mesh copper grids (Ted Pella, Inc., Redding, CA, USA). Sections were stained with $2 \%$ uranyl acetate and Reynolds lead citrate and then analyzed using transmission electron microscopy (EM 10A Zeiss). 


\section{mRNA detection}

mRNA was assessed by nanostring analysis [25]. nCounter CodeSets were constructed for detecting selected human-specific genes. A total of $1 \times 10^{4}$ cells of each subset were lysed in RLT buffer (QIAGEN) supplemented with $\beta$-mercaptoethanol. This lysate was mixed with capture and reporter probes, hybridized to the Codeset for $16 \mathrm{hr}$ and loaded onto the nCounter prep station, and then quantified with the nCounter Digital Analyzer. For sideby-side comparisons of nCounter experiments, data were normalized in two ways described previously [26]. Briefly, the first normalization was for small variations utilizing the internal positive controls that are present in each CodeSet. Then the samples were normalized with 7 housekeeping genes that were included in the CodeSet. The data was analyzed with $\mathrm{n}$ Solver software. The heatmap was constructed using $\log 2$ transformed data and the Tiger Multi Experiment Viewer software.

\section{Statistical analysis}

Statistical analysis was performed using GraphPad Prism software, version 5.0. The results were analyzed using two-tailed paired t-test. Wilcoxon testing was used when data did not fit a Gaussian distribution. The results were analyzed using unpaired ttest when two groups were compared. Mann-Whitney (MW) test was used when a normality test failed. Analyses were also done between HD (represented in the graphs as dashed line) and patients after cure and no significant differences were found. The correlation analyses were performed using the Spearman's rank. Differences were considered to be statistically significant, when $p \leq$ 0.05 .

\section{Results}

$P$. vivax-infected patients display higher levels of plasma cytokines accompanied by increased frequencies of circulating monocytes

High levels of the pro-inflammatory cytokines, IL-6 and IL-8, and regulatory cytokine IL-10, were found in the circulation of $P$. vivax-infected patients before treatment initiation, when compared to the same patients after anti-malarial therapy (Figure 1A). While the cytokinemia of $P$. vivax-infected patients was significantly higher than individuals after cure, the absolute numbers of total leukocytes decreased with infection (Figure 1B). The frequencies of lymphocytes were lower, whereas the proportions of polymorphonuclear cells and monocytes were higher in symptomatic malaria patients. Monocyte frequencies were also assessed within PBMC by flow cytometry. The frequencies of $\mathrm{CD}_{1} 4^{+}$monocytes were significantly higher in $P$. vivax-infected patients than in the same individuals after treatment (Figure 1C).

\section{$P$. vivax infection alters the expression of HLA-DR, adhesion molecules and chemokine receptors on circulating monocytes}

The expression of the activation marker, HLA-DR, cell adhesion molecules, CD54, CD106, CD31, and chemokine receptors, CXCR3, CGR7, was analyzed on circulating monocytes (Figure 2). Significantly lower levels of HLA-DR were found on monocytes from $P$. vivax-infected patients when compared to the same patients after treatment (Figure 2). Monocytes from acute malaria patients also displayed significantly lower levels of the adhesion molecule CD31 and the chemokine receptor CCR7 (Figure 2). In contrast, significantly higher expression of the adhesion molecules CD106 (VCAM-1), CD54 (ICAM-1), and the chemokine receptor CX3CR1, were observed on monocytes from acute malaria patients before treatment initiation (Figure 2). The expression of all these molecules on monocytes from malaria patients reached the levels found in healthy donors when analyzed 30 days after treatment. Thus, monocytes from $P$. vivax-infected patients exhibit a distinct activation state during acute infection.

\section{Monocyte subpopulations from $P$. vivax-infected patients display distinct activated phenotypes}

As noted above, human monocyte subsets can be distinguished by flow cytometry based on the expression of CD14 and CD16 [18]. The majority of monocytes express CD14 but not CD16, and those expressing CD16 can be subdivided into two subpopulations, $\mathrm{CD} 14^{+} \mathrm{CD} 16^{+}$and $\mathrm{CD} 14^{\mathrm{lo}} \mathrm{CD} 16^{+}$cells (Figure $3 \mathrm{~A}$ ). They are also slightly different in granularity as previously described and shown in Figure S1 [18]. To exclude any contaminating neutrophils, only HLA-DR ${ }^{+}$cells were included in the analysis and $\mathrm{CD} 16^{+}$cells were included only if they also expressed HLA-DR. Higher frequencies of $\mathrm{CD} 14^{+} \mathrm{CD} 16^{-}$monocytes were found in $P$. vivaxinfected patients when compared with patients after treatment (Figure 3B). The frequencies of CD $14^{+} \mathrm{CD} 16^{+}$and $\mathrm{CD} 14^{\mathrm{lo}} \mathrm{CD} 16^{+}$ monocytes did not differ significantly between malaria patients before and after treatment.

Chemokine receptors and the adhesion molecule, LFA-1, have been reported to be differently expressed on monocyte subsets. Previous studies described that CGR2 is expressed by both $\mathrm{CD}_{1} 4^{+} \mathrm{CD} 16^{-}$and $\mathrm{CD} 14^{+} \mathrm{CD} 16^{+}$but not by $\mathrm{CD} 14^{\mathrm{lo}} \mathrm{CD} 16^{+}$ monocytes $[18,27]$. Similarly in $P$. vivax-infected patients, low levels of CCR2 were found in $\mathrm{CD} 14^{+} \mathrm{CD} 16^{-}$and $\mathrm{CD} 14^{+} \mathrm{CD} 16^{+}$ monocytes and, as expected, GCR2 was barely expressed by $\mathrm{CD} 14^{\mathrm{lo}} \mathrm{CD} 16^{+}$cells (Figure 3C and 3D). In addition, no changes in LFA-1 expression in the different monocyte subsets were observed in $P$. vivax patients as a result of treatment (Figure $3 \mathrm{G}$ ). Higher LFA-1 levels were observed in $\mathrm{CD} 14^{+} \mathrm{CD} 16^{+}$, followed by $\mathrm{CD} 14^{\mathrm{lo}} \mathrm{CD} 16^{+}$and $\mathrm{CD} 14^{+} \mathrm{CD} 16^{-}$monocytes (Figure 3D). The expression of CX3CR1 along with LFA-1 has been implicated in the ability of $\mathrm{CD} 14^{\mathrm{lo}} \mathrm{CD} 16^{+}$monocytes to crawl on the inner surface endothelium of blood vessels $[18,28]$. Importantly, $P$. vivax infection triggered a significantly increased expression of CX3CR 1 on $\mathrm{CD} 14^{+} \mathrm{CD} 16^{-}, \mathrm{CD} 14^{+} \mathrm{CD} 16^{+}$and $\mathrm{CD} 14^{\mathrm{lo}} \mathrm{CD} 16^{+}$ monocytes (Figure 3C). CX3CR1 was expressed at lower levels by $\mathrm{CD}_{14}{ }^{+} \mathrm{CD} 16^{-}$monocytes, when compared to the $\mathrm{CD} 16^{+}$ populations (Figure 3D). Lastly, changes in CCR7 expression were observed only on $\mathrm{CD} 14^{+} \mathrm{CD} 16^{-}$monocytes, with those from $P$. vivax infected patients expressing lower levels of CCR7 compared to monocytes from treated individuals (Figure 3G). Thus, all the monocyte subpopulations from $P$. vivax-infected display a distinct phenotypic profile in patients undergoing acute malaria compared with the same individuals after treatment.

\section{$P$. vivax induces a variety of inflammatory genes during malaria infection}

We next FACS-sorted the $\mathrm{CD} 14^{+} \mathrm{CD} 16^{-}, \mathrm{CD} 14^{+} \mathrm{CD} 16^{+}$and $\mathrm{CD} 14^{\mathrm{lo}} \mathrm{CD} 16^{+}$monocyte subpopulations from healthy donors and $P$. vivax-infected patients (Figure 4A). The purity of each cell population is shown in Figure 4A. Since the numbers of each circulating monocyte subset obtained from the FACS-sort was limited, we chose to assess the expression of several genes involved in inflammatory responses by nanostring [25]. The expression of 72 selected genes involved in innate immune response, cell adhesion, migration and phagocytosis was evaluated, and we found that 41 genes had their expression significantly altered in at least one of the monocyte subpopulations upon $P$. vivax infection (Figure 4B). Differences greater than 4-fold cannot be appreciated 
A

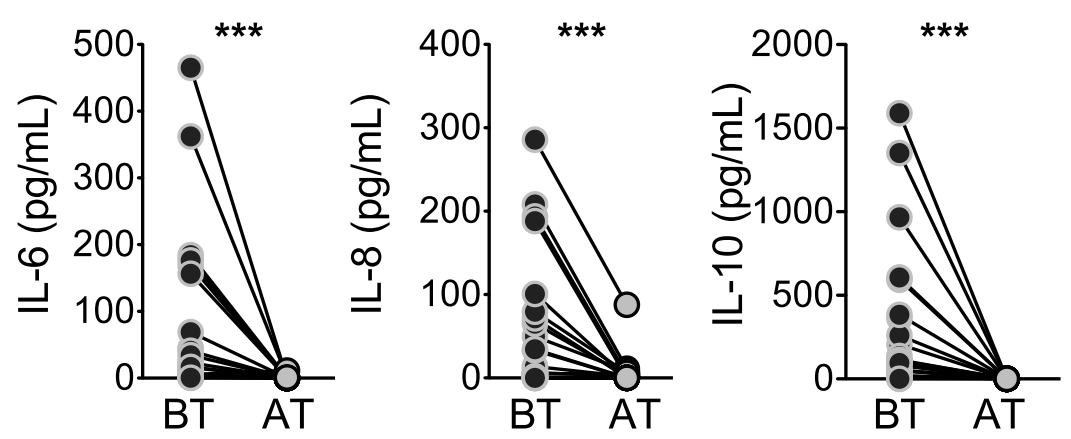

B
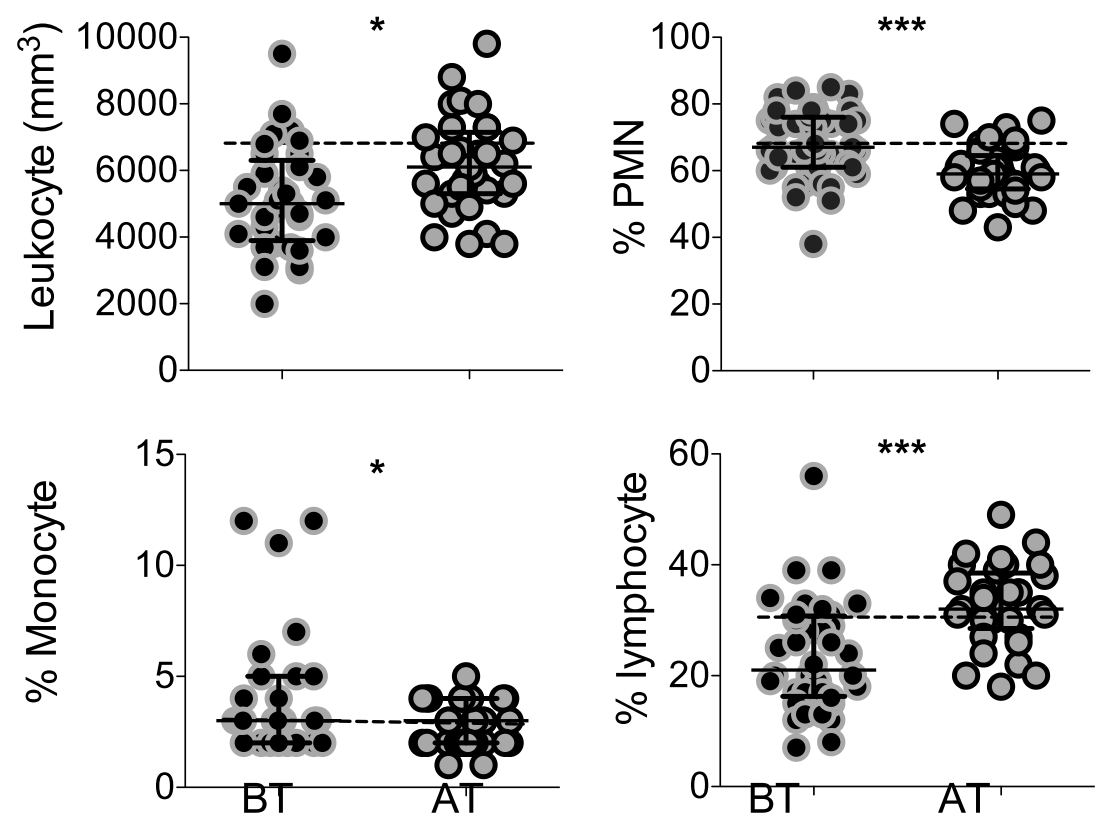

C
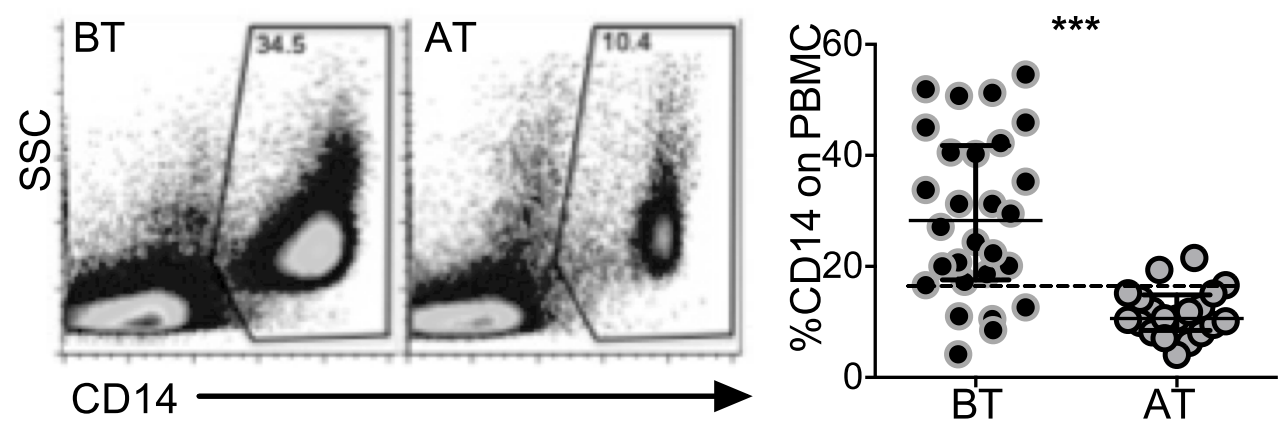

Figure 1. $P$. vivax-infected patients display higher levels of cytokines accompanied by increased frequencies of circulating monocytes. (A) IL-6, IL-8 and IL-10 were measured in plasma of $P$. vivax-infected individuals before (BT, black circles) and 30-45 days after (AT, grey circles) treatment $(n=20)$. Levels of cytokine were measured by Cytometric Bead Array. (B) Leukocyte counts and frequencies from $P$. vivax-infected individuals before (BT, black circles) and after (AT, grey circles) treatment were assessed at a clinical laboratory $(n=33)$. C) Representative density plots of $\mathrm{CD}_{14}^{+}$monocytes (left panel) and frequencies of $\mathrm{CD} 14^{+}$monocytes (right panel) within PBMCs from $P$. vivax-infected individuals (BT, $\mathrm{n}=28$ and $\mathrm{AT}$, $\mathrm{n}=20$ ). Circles indicate individual patients and lines represent median values and interquartile ranges. Dotted lines represent medians of a given measurements from healthy donors. ${ }^{*} p<0.05,{ }^{* * *} p<0.01$. doi:10.1371/journal.ppat.1004393.g001 

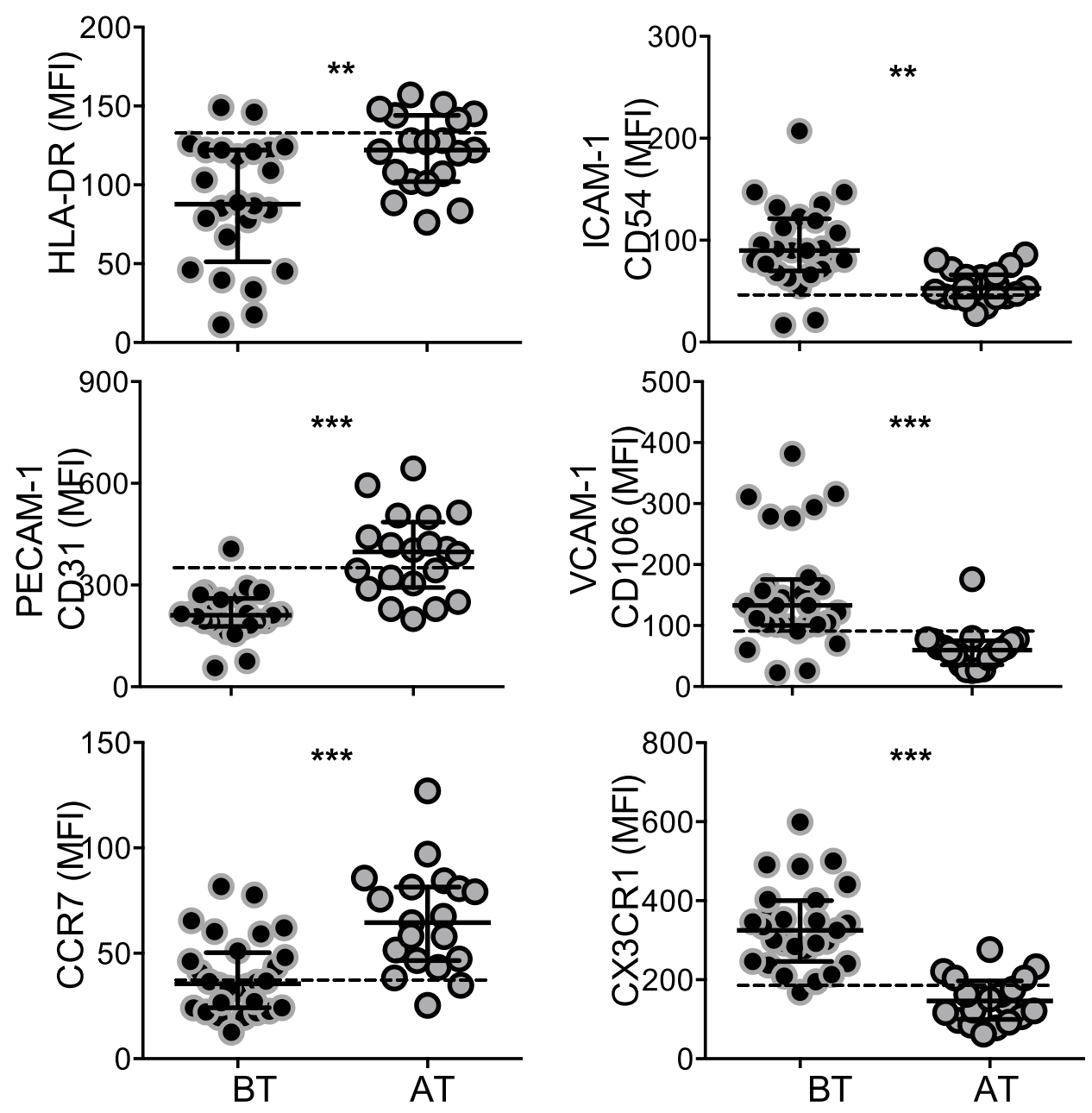

\section{P. vivax-infected patients

\begin{tabular}{|l|l} 
HLA-DR & ICAM-1 \\
PECAM-1 & VCAM-1 \\
CCR7 & CX3CR1
\end{tabular}

Figure 2. $P$. vivax infection alters the expression of activation markers, adhesion molecules and chemokine receptors on circulating monocytes. Mean fluorescence intensity (MFI) of HLA-DR (BT, $n=24$ and AT, $n=19), C D 31$ (BT, $n=25$ and AT, $n=20), C C R 7$ (BT, $n=28$ and AT, $n=19$ ) (left panels, from the top to the bottom), CD54 (BT, $n=25$ and AT, $n=19), C D 106$ (BT, $n=28$ and AT, $n=19), C X 3 C R 1$ (BT, $n=28$ and AT, $n=20$ ) (right panels, from the top to the bottom) was evaluated on monocytes from P. vivax-infected subjects, before (BT, black circles) and 30-45 days after treatment (AT, grey circles). Circles indicate individual patients and lines represent median values and interquartile ranges. Dotted lines represent medians of a given measurements from healthy donors. Levels of the molecules above were measured by flow cytometry. ${ }^{* *} 0.05>p>0.01,{ }^{* * *} p<$ 0.01 .

doi:10.1371/journal.ppat.1004393.g002

in the heatmap, once the range from -4.0 to +4.0 fold was selected to better reveal differences in the majority of the genes induced by malarial infection in monocyte subsets. Once changes in gene expression were detected upon $P$. vivax infection, the expression of each of these genes was compared among the monocytes subset from $P$. vivax-infected patients (Figure $4 \mathrm{C}$ ). In general, the $\mathrm{CD}_{14}{ }^{+}$subpopulations, i.e., the classical and inflammatory monocytes, expressed higher levels of RNAs encoded by pro-inflammatory genes. The chemokines CGL2 and CXCL2 were highly expressed by $\mathrm{CD}_{1} 4^{+} \mathrm{CD} 16^{-}$and $\mathrm{CD} 14^{+} \mathrm{CD} 16^{+}$subpopulations, but were expressed at lower levels by $\mathrm{CD} 14^{\mathrm{lo}} \mathrm{CD} 16^{+}$monocytes (Figure $4 \mathrm{C}$ ). The same pattern of expression was observed for TNFR1/TNFRSF1A and ICAM-1 with $\mathrm{CD} 14^{+} \mathrm{CD} 16^{-}$and $\mathrm{CD} 14^{+} \mathrm{CD} 16^{+}$expressing higher levels than $\mathrm{CD} 14^{\mathrm{lo}} \mathrm{CD} 16^{+}$monocytes (Figure $4 \mathrm{C}$ ). The classical monocytes, $\mathrm{CD} 14^{+} \mathrm{CD} 16^{-}$expressed higher counts of mRNA for the receptor for IFN-gamma and for the IL-1 receptor agonist IL-1RA (Figure 4C). The expression of cytokine genes also varied among monocyte subsets. Both IL6 and ILIO had higher expression in $\mathrm{CD} 14^{+} \mathrm{CD} 16^{+}$compared to $\mathrm{CD} 14^{+} \mathrm{CD} 16^{-}$cells. $\mathrm{CD} 14^{\mathrm{lo}} \mathrm{CD} 16^{+}$ monocytes expressed higher levels of mRNA for TNF and lower levels of $I L 8$ than the $\mathrm{CD} 14^{+} \mathrm{CD} 16^{-}$subset. $\mathrm{CD} 14^{+} \mathrm{CD} 16^{-}$as well as $\mathrm{CD} 14^{+} \mathrm{CD} 16^{+}$monocytes expressed higher amounts of NLRP 3 and CASPASE 1 than patrolling monocytes. The same 
A

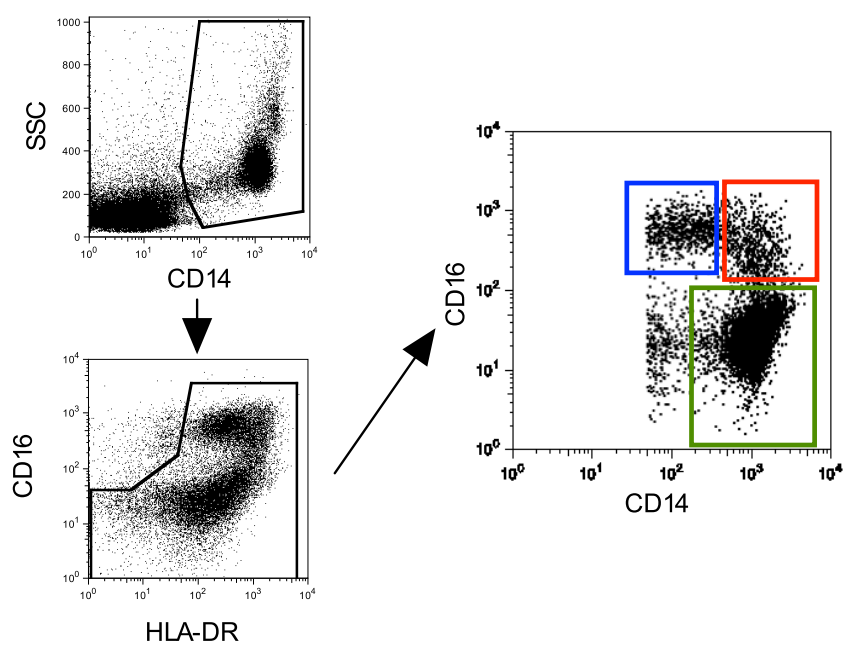

C
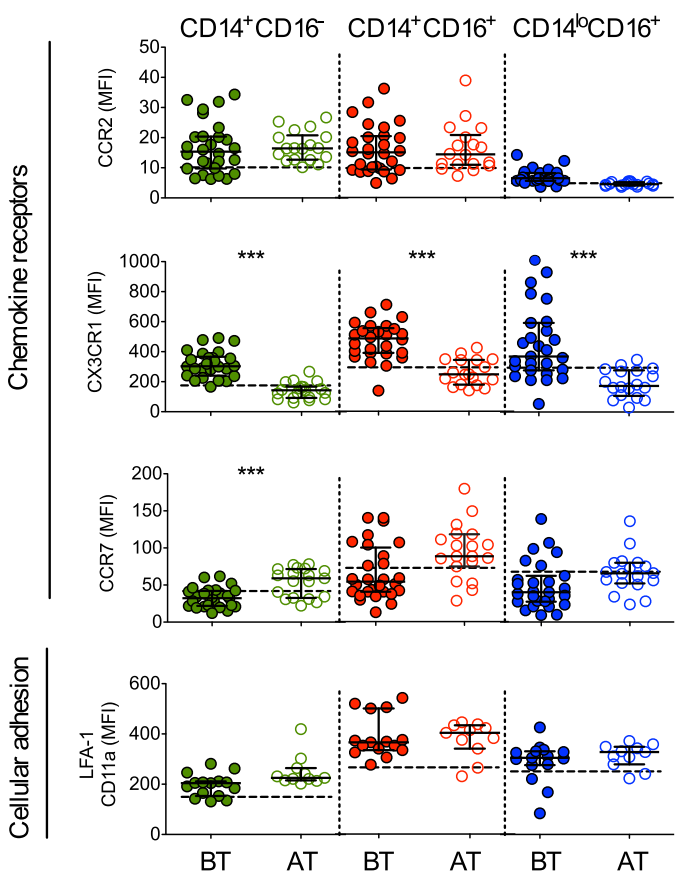

E

\begin{tabular}{|c|c|c|c|}
\cline { 2 - 4 } \multicolumn{1}{c|}{} & $\mathrm{CD} 14^{+} \mathrm{CD}_{16}$ & $\mathrm{CD}^{4} 4^{+} \mathrm{CD}_{16}{ }^{+}$ & $\mathrm{CD}^{\circ} 4^{\mathrm{l}} \mathrm{CD} 16$ \\
\hline CCR2 & ++ & ++ & + \\
\hline CXCR3 & ++ & +++ & +++ \\
\hline CCR7 & + & +++ & ++ \\
\hline LFA-1 & + & +++ & ++ \\
\hline
\end{tabular}

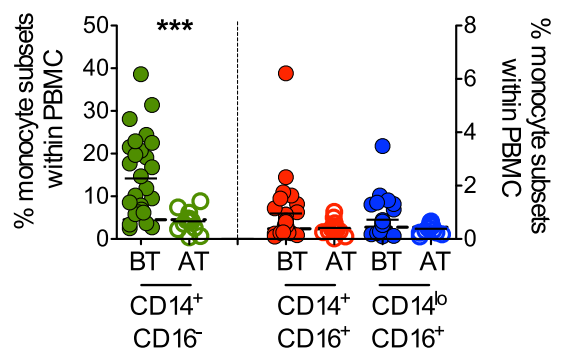

$\mathrm{D}$
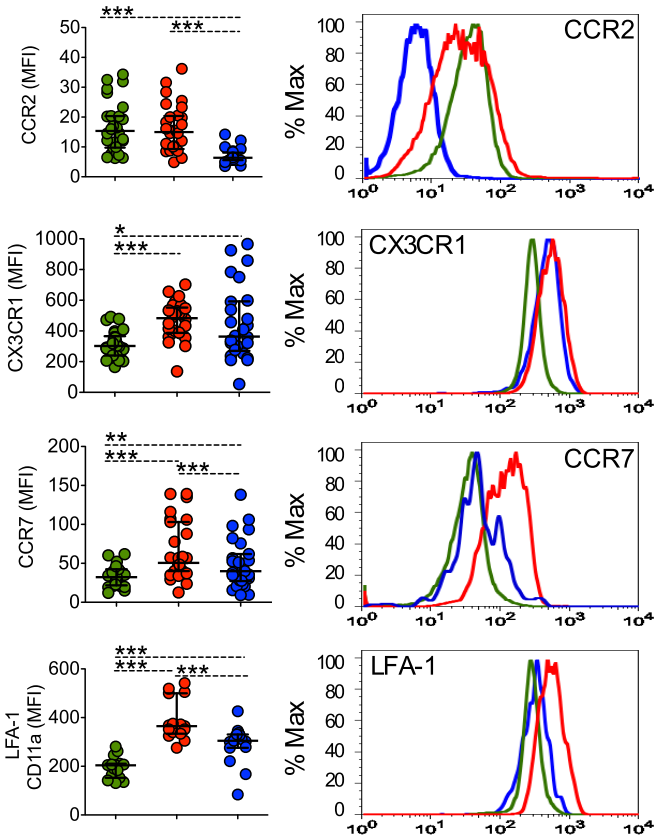

$\square \mathrm{CD} 14^{+} \mathrm{CD} 16$ $\square \mathrm{CD} 14^{+} \mathrm{CD} 16^{+}$ $\square \mathrm{CD} 14^{\mathrm{lo}} \mathrm{CD} 16^{+}$

Figure 3. Characterization of monocyte subsets in malaria patients. (A) Representative dot plots showing the gate strategy for the identification of $\mathrm{CD} 14^{+} \mathrm{CD} 16^{-}$(green gate), $\mathrm{CD} 14^{+} \mathrm{CD} 16^{+}$(red gate), $\mathrm{CD} 14^{\mathrm{l}} \mathrm{CD} 16^{+}$(blue gate) monocyte subsets. CD $14^{+} \mathrm{CD} 16^{-}, \mathrm{CD} 14^{+} \mathrm{CD} 16^{+}$and $\mathrm{CD} 14^{\mathrm{lo}} \mathrm{CD} 16^{+}$monocytes are represented by green, red and blue symbols. (B) Frequencies of $\mathrm{CD} 14^{+} \mathrm{CD} 16^{-}, \mathrm{CD} 14^{+} \mathrm{CD} 16^{+}$and $\mathrm{CD} 14^{\mathrm{lo}}$ monocytes within PBMC from P. vivax-infected patients before (BT, filled symbols) and 30-45 days after treatment (AT, open symbols) $(n=28)$. (C) Mean fluorescence intensity (MFI) of CCR2 (BT, $n=28$ and AT, $n=18), C X 3 C R 1$ (BT, $n=26$ and $A T, n=19), C C R 7(B T, n=28$ and AT, $n=19)$ and LFA-1 (BT, $n=15$ and $A T, n=11$ ) (from the top to the bottom) was evaluated on monocyte subsets (CD $14^{+} C D 16^{-}$(left panel), CD $14^{+} C D 16^{+}$(middle panel), $\mathrm{CD} 14^{\mathrm{lo}} \mathrm{CD} 16^{+}$(right panel)) from P. vivax-infected subjects, before and 30-45 days after treatment. Dotted lines represent medians of a given measurements from healthy donors. (D) Scattered dot plots (left panels) and representative histograms (right panels) showing MFI of the molecules 
described above on $\mathrm{CD} 14^{+} \mathrm{CD} 16^{-}, \mathrm{CD} 14^{+} \mathrm{CD} 16^{+}$and $\mathrm{CD} 14^{10} \mathrm{CD} 16^{+}$monocytes from $P$. vivax-infected patients before treatment (open histograms). Levels of the molecules above were measured by flow cytometry. Circles indicate individual patients and lines represent median values and interquartile ranges. (E) Levels of molecules expressed by the monocyte subsets analyzed according to D. ${ }^{*} p<0.05,{ }^{* *} 0.05>p>0.01,{ }^{* * *} p<0.01$. doi:10.1371/journal.ppat.1004393.g003

pattern of expression was observed for NFKB1 and NFKB1A, involved respectively with induction and regulation of cytokine expression, with $\mathrm{CD} 14^{+} \mathrm{CD} 16^{-}$and $\mathrm{CD} 14^{+} \mathrm{CD} 16^{+}$expressing higher levels than $\mathrm{CD} 14^{\mathrm{lo}} \mathrm{CD} 16^{+}$monocytes. REL that encodes a protein that is a member of the Rel/NFKB family was more highly expressed on $\mathrm{CD}_{1} 4^{+} \mathrm{CD} 16^{+}$monocytes than on the other monocyte subpopulations. The expression of the costimulatory molecule CD80 was higher in $\mathrm{CD} 14^{+} \mathrm{CD} 16^{+}$than classical and patrolling monocytes (Figure 4C). Together these data indicate that $\mathrm{CD} 14^{+} \mathrm{CD} 16^{-}$and $\mathrm{CD} 14^{+} \mathrm{CD} 16^{+}$monocytes have a more activated and inflammatory profile than patrolling monocytes during malaria.

\section{Monocytes from $P$. vivax infected patients exhibit morphologic changes}

Patrolling monocytes can be distinguished from the classical and inflammatory subsets based on size and granularity [18], but no ultrastructural analysis had been previously performed on these cell subpopulations. Electronic microscopy was performed attempting to reveal morphological changes suggestive of functional alterations. FACS-sorted $\mathrm{CD} 14^{+} \mathrm{CD} 16^{-}, \mathrm{CD} 14^{+} \mathrm{CD} 16^{+}$and $\mathrm{CD} 14^{\mathrm{lo}} \mathrm{CD} 16^{+}$monocytes from healthy donors $(\mathrm{n}=5)$ and $P$. vivax-infected patients $(\mathrm{n}=6)$ (Figure $4 \mathrm{~A})$ were fixed and processed for ultrastructural analysis by electron microscopy (Figure $5 \mathrm{~A}) . \mathrm{CD}_{1} 4^{+} \mathrm{CD} 16^{-}$and $\mathrm{CD} 14^{+} \mathrm{CD} 16^{+}$monocytes from $\mathrm{HD}$ (Figure 5A, upper panel) and $P$. vivax-infected patients (Figure 5A, lower panel) had a larger and a higher number of mitochondria (white arrows) when compared to $\mathrm{CD} 14^{\mathrm{lo}} \mathrm{CD} 16^{+}$ monocytes. All monocyte subsets from $P$. vivax-infected patients displayed morphological features compatible with activation (Figure 5A). Moreover, mitochondria from $\mathrm{CD} 14^{+} \mathrm{CD} 16^{+}$cells from $P$. vivax-infected patients were significantly larger than those in the two other monocyte subsets, when mitochondria area was measured using the software Image J 1.47K (NIH) (Figure 5B). Mitochondria area was assessed in at least six cells of each monocyte subpopulation per patient.

ROS are generated in multiple compartments and by multiple enzymes in the cell and important contributions include proteins within the plasma membrane, e.g., NADPH oxidases, and mitochondria [29,30]. Since mitochondria are at least in part responsible for the generation of ROS [31,32], we further assessed the content of mitochondria in the monocyte subsets from $P$. vivax-infected patients. MitoTracker Red CMX-Ros was used for this propose. The MFI of MitoTracker Red, probe sensitive to membrane potential, was assessed in $\mathrm{CD}_{4} 4^{+} \mathrm{CD} 16^{-}$, $\mathrm{CD}_{1} 4^{+} \mathrm{CD} 16^{+}$and $\mathrm{CD} 14^{\text {lo }} \mathrm{CD} 16^{+}$monocyte subsets by flow cytometry (Figure 5C). CD $14^{+} \mathrm{CD} 16^{-}$and $\mathrm{CD} 14^{\mathrm{lo}} \mathrm{CD} 16^{+}$monocytes similarly react with Mitotracker Red while significantly higher reactivity was found in $\mathrm{CD} 14^{+} \mathrm{CD} 16^{+}$monocytes (Figure $5 \mathrm{C}$ ). Our data show that $\mathrm{CD} 14^{+} \mathrm{CD} 16^{+}$monocytes have larger and more active mitochondria suggesting differential metabolic activity during $P$. vivax infection. The expression of $\mathrm{p} 47 \mathrm{phox}$ and p67phox, cytosolic components of the NADPH oxidase, was also measured in monocyte subsets from malaria patients after a shortterm culture with $P$. vivax-infected reticulocytes. Higher expression of p47phox and p67phox were found in $\mathrm{CD} 14^{+} \mathrm{CD} 16^{+}$ monocytes when comparing to their other counterparts (Figure 5D).
Monocyte subpopulations from malaria patients display distinct levels of molecules involved in cell activation and migration

Upon activation monocytes undergo several changes, including expression of molecules involved with antigen presentation, cell adhesion and migration $[33,34,35] . \mathrm{CD} 14^{+} \mathrm{CD} 16^{-}$monocytes from patients undergoing $P$. vivax infection expressed lower levels of HLA-DR (Figure 6A). In contrast, the expression of HLA-DR did not differ in $\mathrm{CD} 14^{+} \mathrm{CD} 16^{+}$and $\mathrm{CD} 14^{\mathrm{lo}} \mathrm{CD} 16^{+}$monocytes when cells from malaria patients were compared before and after treatment (Figure 6A). Higher levels of HLA-DR were found in $\mathrm{CD} 14^{+} \mathrm{CD} 16^{+}$monocytes compared to their other counterparts during $P$. vivax infection (Figure $6 \mathrm{~A}, \mathrm{~B}, \mathrm{G}$ ).

We also observed that $P$. vivax infection triggered the expression of VCAM-1 and ICAM-1 in all three monocyte subpopulations (Figure 6). In contrast, a decreased expression of PECAM-1 was observed in patients experiencing malaria when compared to the same patients after treatment (Figure 6A). Importantly, $\mathrm{CD} 14^{+} \mathrm{CD} 16^{+}$monocytes from $P$. vivax-infected patients expressed the highest levels of ICAM-1 and PECAM-1, when compared to $\mathrm{CD} 14^{+} \mathrm{CD} 16^{-}$and $\mathrm{CD} 14^{\text {lo }} \mathrm{CD} 16^{+}$monocytes (Figure 6B, G). Taken together these results further corroborate that $\mathrm{CD} 14^{+}$monocytes, especially the $\mathrm{CD} 14^{+} \mathrm{CD} 16^{+}$subset, are highly activated during $P$. vivax malaria.

\section{$\mathrm{CD} 16^{+} \mathrm{CD} 14^{+}$monocytes display elevated phagocytosis}

We used CFSE labeled $P$. vivax-infected reticulocytes (Pv-Ret) to quantify phagocytosis by different monocyte subpopulations from malaria patients before treatment initiation. CD $14^{+} \mathrm{CD} 16^{+}$ cells displayed significantly higher levels of phagocytosis of $\mathrm{Pv}$-Ret than the other monocyte subsets (Figure 7A). The phagocytic ability of $\mathrm{CD} 14^{+} \mathrm{CD} 16^{+}$cells was followed by the $\mathrm{CD} 14^{\mathrm{lo}} \mathrm{CD} 16^{+}$ patrolling monocytes, which was significantly better than the $\mathrm{CD}_{14}{ }^{+} \mathrm{CD} 16^{-}$monocytes (Figure 7A). It is important to note that significant differences are found in the phagocytic ability of monocyte subsets when uninfected reticulocytes are purified from healthy donors and co-cultured with PBMC from patients and healthy donors. Much lower frequencies of reticulocytes containing monocytes are detected when cultures are performed with uninfected reticulocytes compared to $P$. vivax-infected reticulocytes (CD14+CD16 ${ }^{-}: 3.54 \% \pm 0.52 \%$ vs. $71.14 \% \pm 11.11 \%$, $\mathrm{CD}_{14}^{+} \mathrm{CD} 16^{+}: \quad 23.20 \% \pm 2.18 \% \quad$ vs. $\quad 98.33 \% \pm 1.40 \%$, $\mathrm{CD} 14^{\mathrm{lo}} \mathrm{CD} 16^{+}: 23.18 \% \pm 4.22 \%$ vs. $\left.87.13 \% \pm 8.10 \%\right)$. The same phenomenon was shown for $P$. falciparum [36].

Interestingly, higher levels of phagocytosis of $\mathrm{Pv}$-Ret correlated with higher expression of the adhesion molecules ICAM-1 (CD54), LFA-1 (CD1 la) and PECAM-1 (CD31) by monocytes (Figure 7B). As adhesion molecules, such as CD54, expressed by cell lines interact with $P$. vivax-infected reticulocytes [22], we used blocking antibodies to assess whether phagocytosis of $P$. vivax-infected erythrocytes was dependent on those interactions. Indeed, the phagocytosis of $\mathrm{Pv}$-Ret by $\mathrm{CD} 14^{+}$cells was partially blocked by either anti-CD54 or -CD1la or -CD31, as observed by the significantly decreased frequencies of monocytes containing $\mathrm{Pv}$ Ret (Figure 7C). To assess the ability of each monocyte subpopulation to kill Pv-Ret, PBMC were left in cultures for $12 \mathrm{~h}$ in the presence of CFSE-labeled-Pv-Ret, and the mean fluorescence intensity of CFSE were measured in each monocyte 


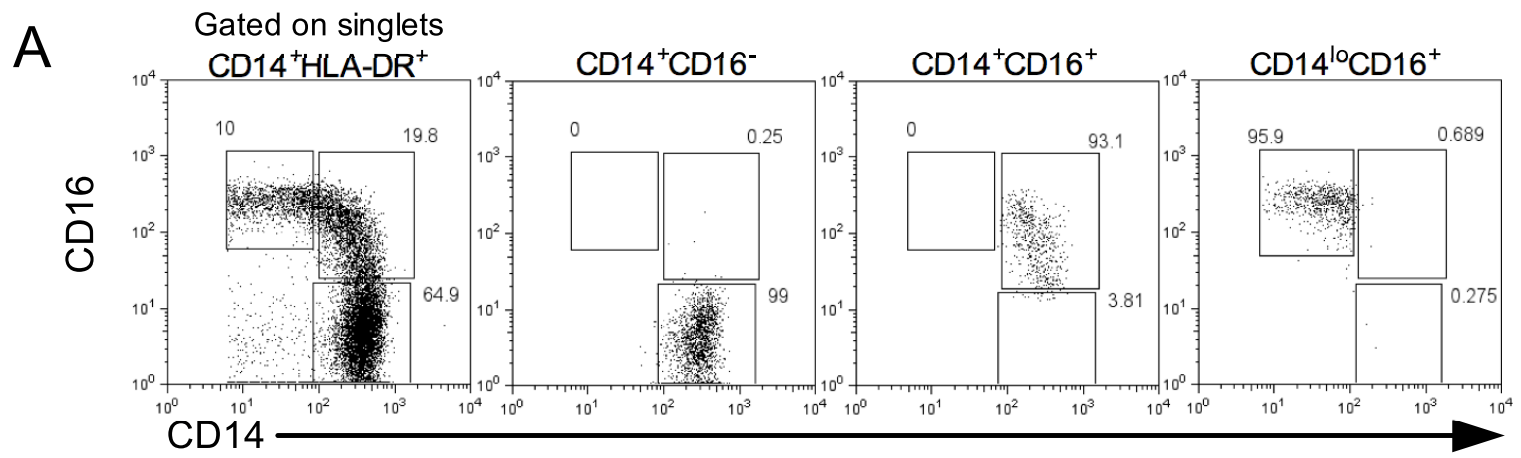

B

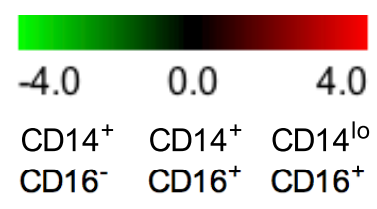

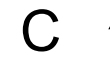
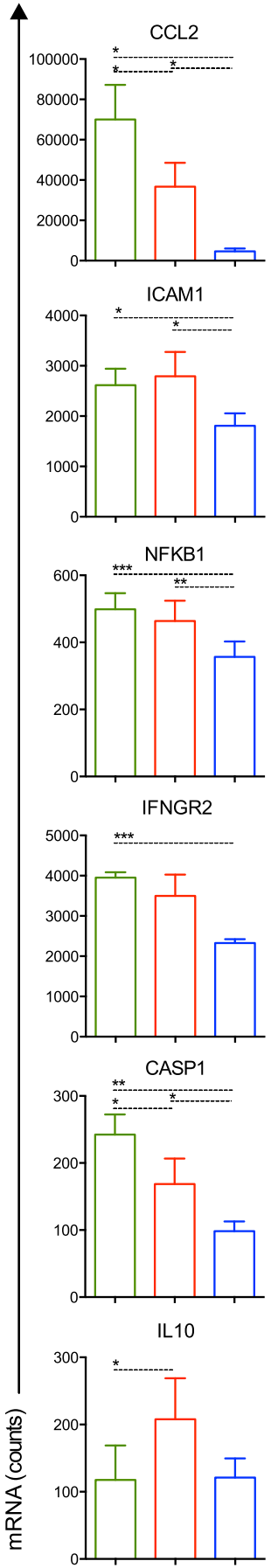
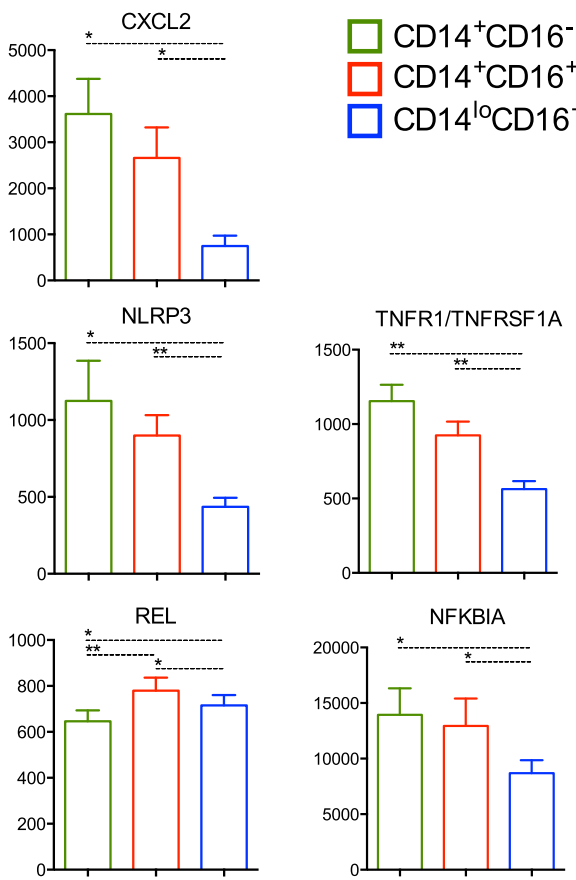

IL1RA

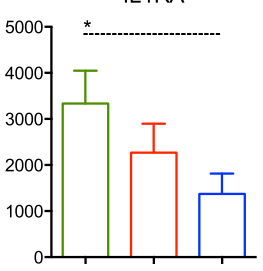

CR1

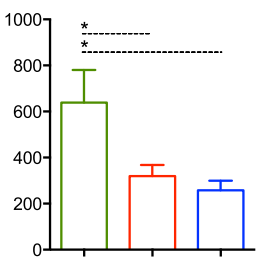

IL6
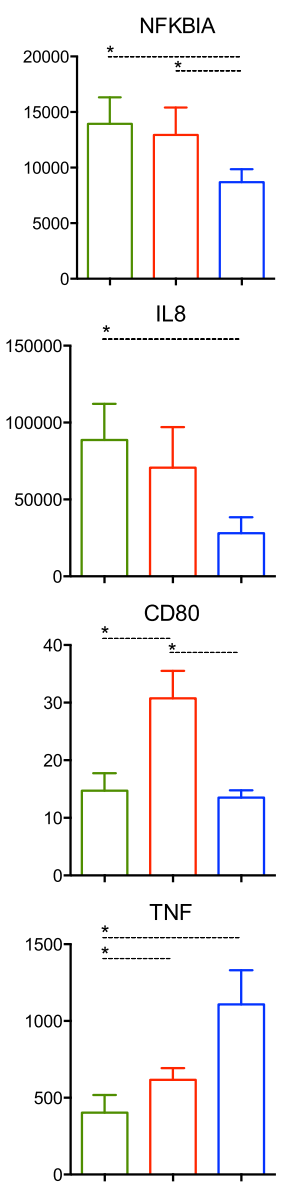
Figure 4. Monocyte subsets display distinct gene expression. $\mathrm{CD} 14^{+} \mathrm{CD} 16^{-}, \mathrm{CD} 14^{+} \mathrm{CD} 16^{+}$and $\mathrm{CD} 14^{\circ} \mathrm{CD} 16^{+}$monocytes from healthy donors and $P$. vivax-infected patients were isolated by FACS. (A) Representative dot plots showing monocyte subpopulations before (left panel) and after FACS-sorting (right panels). (B) A nanostring analysis of monocyte subsets from 5 patients infected with $P$. vivax and 5 healthy donors. Heatmap representation of 41 differentially regulated genes upon malaria infection compared to healthy donors is depicted. (C) CCL2, CXCL2, ICAM1, NLRP3, TNFR1/TNFRSF1A, NFKB1, REL, NFKB1A, IFNGR2, IL1RA, IL8, CASP1, CR1, CD80, IL10, IL6 and TNF were differentially induced among CD14 ${ }^{+} C D 16^{-}$(green bars), $\mathrm{CD} 14^{+} \mathrm{CD} 16^{+}$(red bars) and $\mathrm{CD} 14^{\mathrm{lo}} \mathrm{CD} 16^{+}$(blue bars) monocytes from $P$. vivax-infected patients. ${ }^{*} p<0.05,{ }^{* *} 0.05>p>0.01,{ }^{* * *} p<0.01$. doi:10.1371/journal.ppat.1004393.g004

subset. The MFI of CFSE was only decreased in CD14 $4^{+} \mathrm{CD} 16^{+}$ monocytes when analyzed $12 \mathrm{~h}$ and compared to $4 \mathrm{~h}$ of culture (Figure 7D). Both $\mathrm{CD} 14^{+} \mathrm{CD} 16^{-}$and $\mathrm{CD} 14^{\mathrm{l}} \mathrm{CD}^{+} 6^{+}$displayed similar levels of Pv-Ret containing monocytes when the MFI was compare between 4 and $12 \mathrm{~h}$ of culture. Important to mention that no significant increase in apoptosis or changes in the
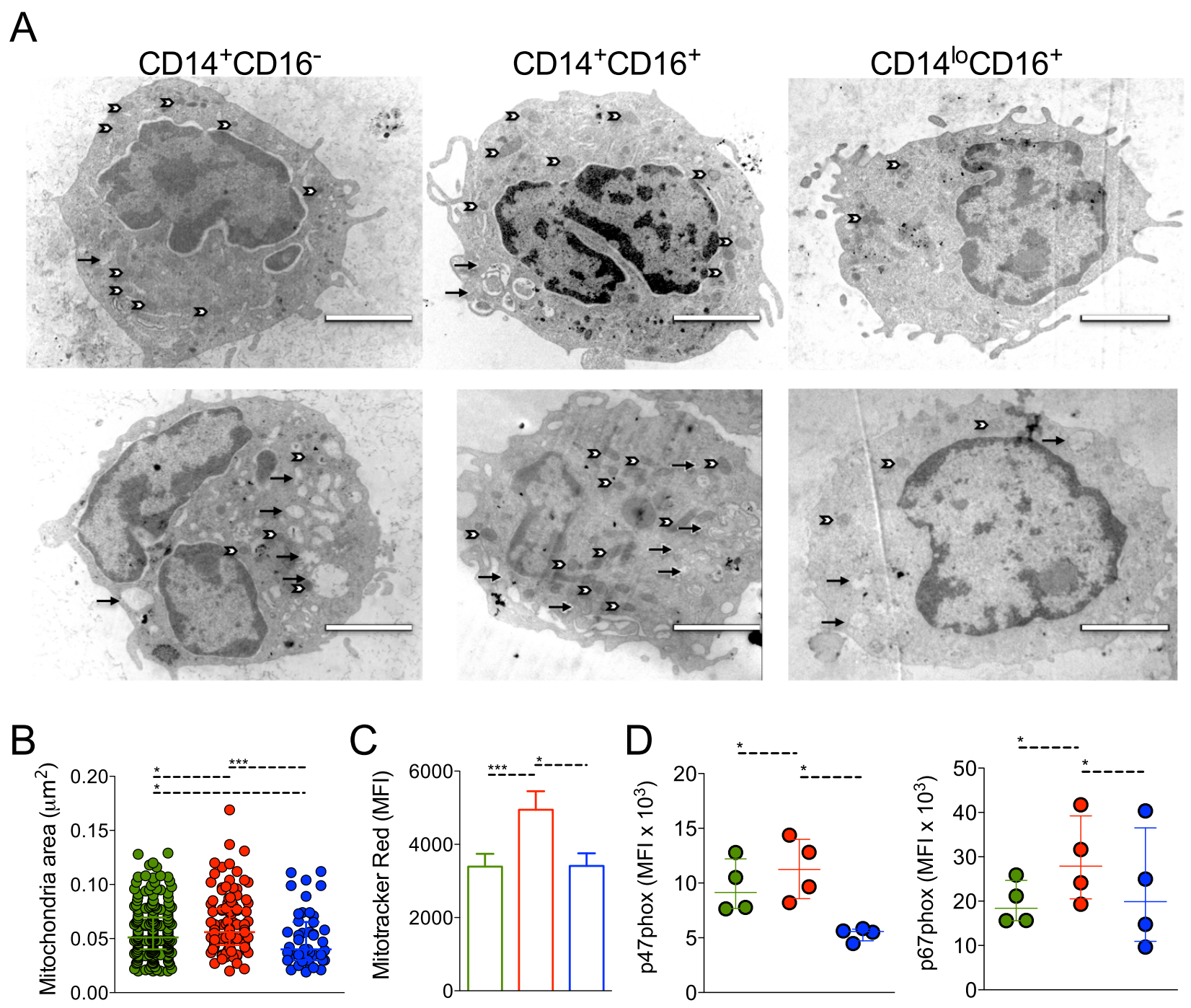

Figure 5. Circulating monocyte subpopulations display distinct morphology, mitochondrial and NADPH subunit content. FACSsorted $\mathrm{CD} 14^{+} \mathrm{CD} 16^{-}, \mathrm{CD} 14^{+} \mathrm{CD} 16^{+}$and $\mathrm{CD} 14^{\mathrm{lo}} \mathrm{CD} 16^{+}$monocytes from healthy donors and $P$. vivax-infected patients were fixed and prepared for electron microscopy. Monocyte subsets from a single healthy donor ( $A$, upper panel) and a single patient ( $A$, lower panel) shown are representative of the analysis of at least six cells of each monocyte subpopulation per patient and of the analysis of 5 controls and 6 patients. Mitochondria (white arrows) and vesicles (black arrows). Scale bar, $2 \mu \mathrm{m}$. (B) Mitochondria area from CD14 CD16 ${ }^{-}$(green circles), CD14 $4^{+} \mathrm{CD} 16^{+}$(red circles) and $\mathrm{CD} 14^{\mathrm{lo}} \mathrm{CD} 16^{+}$(blue circles) monocytes was assessed using ImageJ. Circles indicate individual mitochondria. (C) Mitochondria content in $\mathrm{CD}^{2} 4^{+} \mathrm{CD} 16^{-}$ (green bars), $\mathrm{CD} 14^{+} \mathrm{CD} 16^{+}$(red bars) and $\mathrm{CD} 14^{\mathrm{l}} \mathrm{CD} 16^{+}$(blue bars) monocytes from $P$. vivax-infected patients was measured based on Mitotracker reactivity $(n=11)$. (D) Mean fluorescence intensity (MFI) of p47phox and p67phox within $C D 14^{+} \mathrm{CD} 16^{-}, \mathrm{CD} 14^{+} \mathrm{CD} 16^{+}, \mathrm{CD} 14^{\mathrm{lo}} \mathrm{CD} 16^{+}$monocytes from $P$. vivax-infected patients was measured by flow cytometry 3 hours after culture in medium alone or $P$. vivax-infected reticulocytes $(n=4)$. Results are representative of 2 independent experiments. Symbols represent individual subject. ${ }^{*} p<0.05,{ }^{* * *} p<0.01$.

doi:10.1371/journal.ppat.1004393.g005 

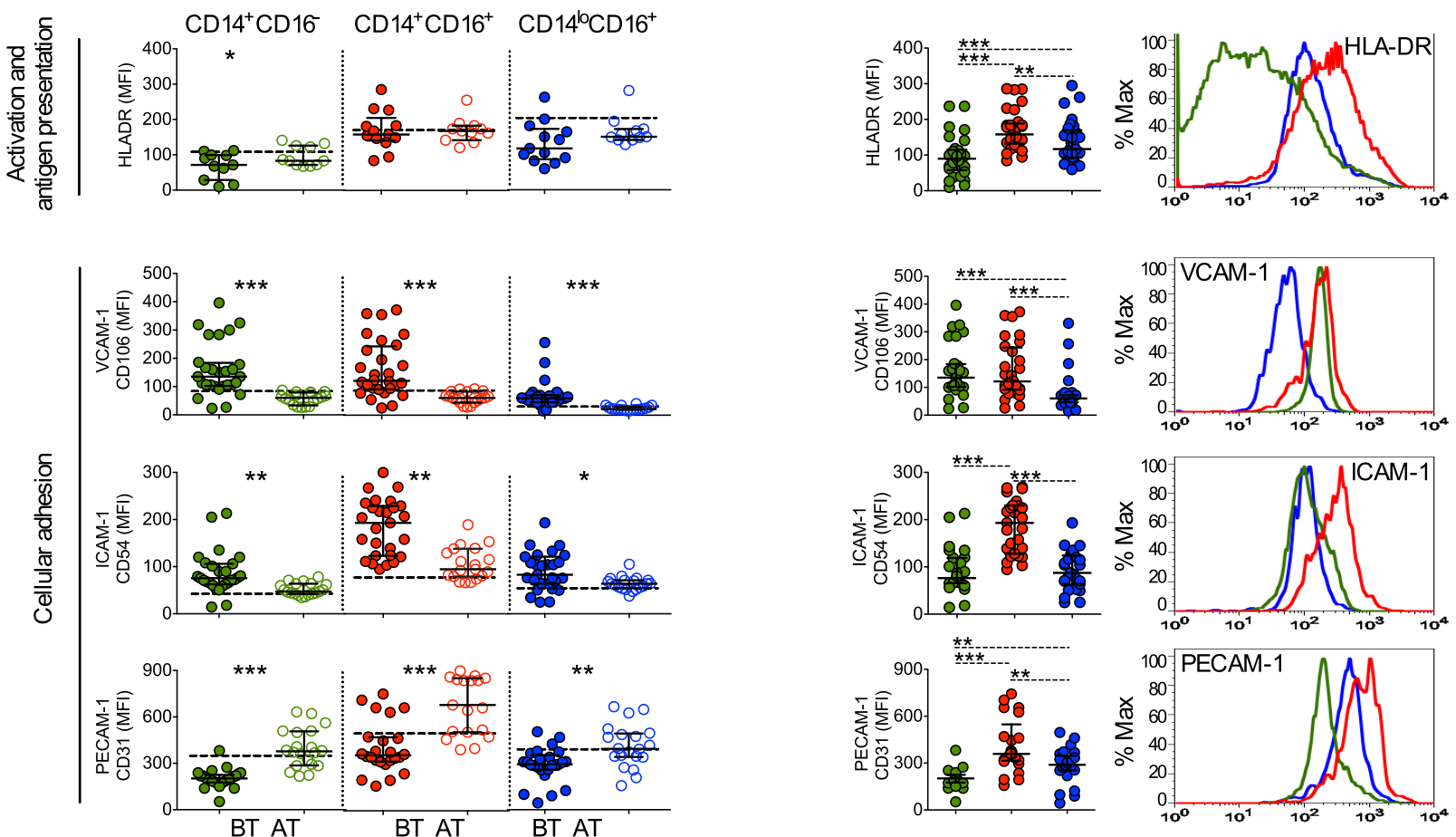

C

\begin{tabular}{|c|c|c|c|}
\cline { 2 - 4 } \multicolumn{1}{c|}{} & $\mathrm{CD}^{\mathrm{c}} 4^{+} \mathrm{CD} 16^{-}$ & $\mathrm{CD}^{+} 4^{+} \mathrm{CD} 16^{+}$ & $\mathrm{CD}^{\mathrm{lo}} \mathrm{CD}^{\mathrm{C}} 6^{+}$ \\
\hline HLA-DR & + & +++ & ++ \\
\hline VCAM-1 & +++ & +++ & ++ \\
\hline ICAM-1 & ++ & +++ & ++ \\
\hline PCAM-1 & + & +++ & ++ \\
\hline
\end{tabular}

Figure 6. Monocyte subsets from $\boldsymbol{P}$. vivax-infected patients display a highly activated phenotype. CD $14^{+} \mathrm{CD} 16^{-}, \mathrm{CD} 14^{+} \mathrm{CD} 16^{+}$and $\mathrm{CD} 14^{\mathrm{lo}} \mathrm{CD} 16^{+}$monocytes are represented by green, red and blue symbols. (A) Mean fluorescence intensity (MFI) of HLA-DR (BT, $n=11$ and AT, $\left.n=11\right)$, CD106 (BT, $n=26$ and AT, $n=19), C D 54(B T, n=28$ and AT, $n=19)$ and CD31 (BT, $n=25$ and AT, $n=20$ ) (from the top to the bottom) was evaluated on monocyte subsets $\left(\mathrm{CD} 14^{+} \mathrm{CD} 16^{-}\right.$(left panel), $\mathrm{CD} 14^{+} \mathrm{CD} 16^{+}$(middle panel), CD14 ${ }^{\mathrm{lo}} \mathrm{CD} 16^{+}$(right panel)) from $P$. vivax-infected subjects, before (filled symbols) and 30-45 days after treatment (open symbols). Dotted lines represent medians of given measurements from healthy donors. (B) Scattered dot plots (left panels) and representative histograms (right panels) showing MFI of the molecules described above on $\mathrm{CD} 14^{+} \mathrm{CD} 16^{-}, \mathrm{CD} 14^{+} \mathrm{CD} 16^{+}$and $\mathrm{CD} 14^{\text {lo }} \mathrm{CD} 16^{+}$monocytes from $P$. vivax-infected patients before treatment. Levels of the molecules above were measured by flow cytometry. Circles indicate individual patients and lines represent median values and interquartile ranges. (C) Levels of molecules expressed by the monocyte subsets analyzed according to B. ${ }^{*} p<0.05,{ }^{* *} 0.05>p>0.01,{ }^{* * *} p<0.01$.

doi:10.1371/journal.ppat.1004393.g006

proportions of monocyte subsets were detected when PBMC were cultured for 4 and 12 hours in medium or Pv-Ret (Figure S2) (Text $\mathrm{S} 1)$.

Higher levels of intracellular TNF and ROS are found in $\mathrm{CD} 14^{+} \mathrm{CD} 16^{+}$monocytes compared to their other counterparts

To examine the mechanism of killing, we evaluated the ability of the different monocytes to produce TNF- $\alpha$ and ROS, which are key effector molecules made by activated monocyte/macrophages. Significantly higher frequencies of TNF- $\alpha$ producing cells were found among $\mathrm{CD} 14^{+} \mathrm{CD} 16^{+}$monocytes when PBMC were cultured with Pv-Ret (or LPS) (Figure 7E).
ROS production by PBMC and monocyte subsets from $P$. vivax-infected patients was measured by luminescence (RLU) of luminol or fluorescence (RFU) of $\mathrm{H}_{2}$ DCFDA (Figure S4). PBMC from $P$. vivax-infected patients produced detectable amounts of total ROS spontaneously or in response to PMA, when measured by luminol (Figure S4A) (Text S1). PBMC from acutely infected patients produce higher levels of ROS than the same patients after treatment. In addition, total ROS production was measured in purified monocyte subsets, but no significant differences were found among them (Figure S4B). Intracellular ROS production by each monocyte subpopulation was also measured in the single-cell level by flow cytometry. Consistent with the phagocytosis and TNF- $\alpha$ results, $\mathrm{CD} 14^{+} \mathrm{CD} 16^{+}$monocytes exposed to Pv-Ret 
A
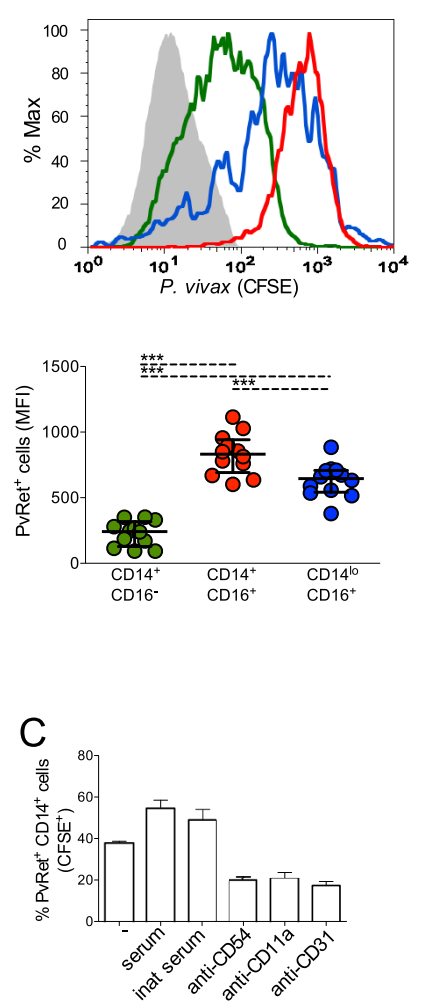

B
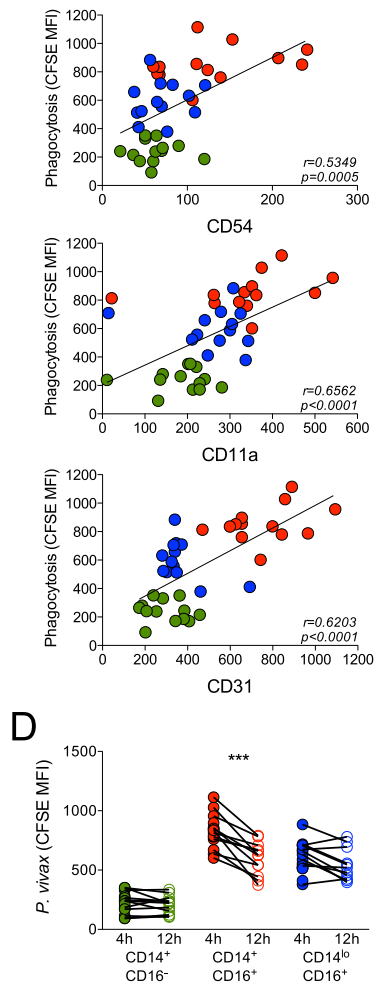

E

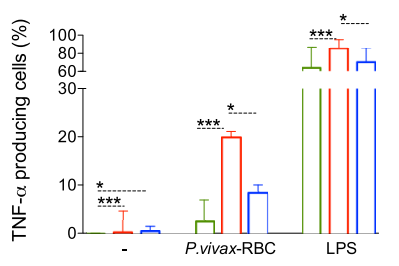

F

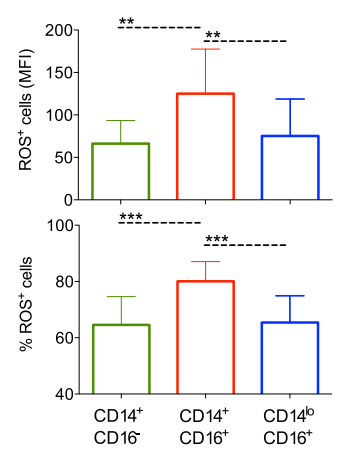

G
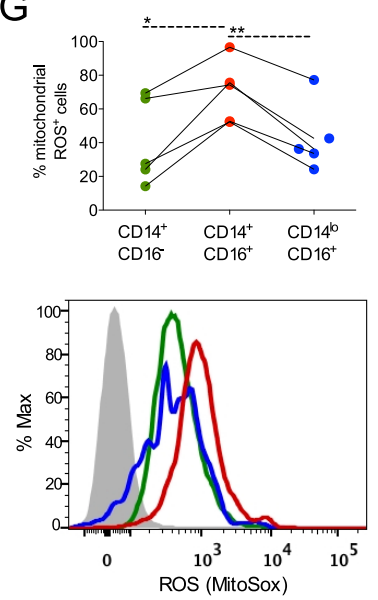

$\square \mathrm{CD} 14^{+} \mathrm{CD} 16-$
$\square \mathrm{CD} 14^{+} \mathrm{CD} 16^{+}$ $\square \mathrm{CD} 14^{\circ} \mathrm{CD} 16^{+}$

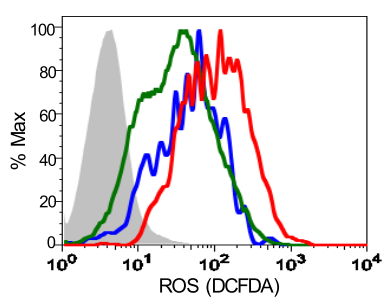




\section{Discussion}

Although pro-inflammatory cytokines play an important role in host resistance to Plasmodium infection, various studies reported that they may contribute to deleterious effects during malaria $[40,41,42]$. Thus, the pathways involved on induction of these mediators during malaria, represent checkpoints for immunological intervention to prevent poor outcome of disease. Monocytes have been described as a major source of cytokines during $P$. vivax infection [5]. Although infection with Plasmodium spp is known to dramatically alter monocyte differentiation [43], the role of monocyte subsets in host resistance to infection and pathogenesis of malaria remains poorly understood. The findings reported here clearly demonstrate that both the classical $\left(\mathrm{CD} 14^{+} \mathrm{CD} 16^{-}\right)$and intermediate or inflammatory $\left(\mathrm{CD} 14^{+} \mathrm{CD} 16^{+}\right)$monocytes are important sources of cytokines during acute $P$. vivax infection. Intriguingly, the $\mathrm{CD} 14^{+} \mathrm{CD} 16^{+}$cells displayed the highest mitochondria content and activity, being an important source of ROS and were the most efficient phagocytes of $P$. vivax infected reticulocytes.

Both in mice and human, different monocyte subsets seem to reflect developmental stages with distinct physiological roles, such as recruitment to inflammatory lesions or entry to normal tissues [17]. Consistent with our results assessing the monocyte subsets in $P$. vivax-infected patients, the majority of monocytes found in steady state, known as classical monocytes, express CD14 but not CD16, and the remaining monocytes express both CD14 and CD16: $\mathrm{CD} 14^{+} \mathrm{CD} 16^{+}$(inflammatory) and $\mathrm{CD} 14^{\text {lo }} \mathrm{CD} 16^{+}$(patrolling) monocytes [18]. This classification still gives rise to discussion. Ziegler-Heitbrock and coworkers has defined $\mathrm{CD} 14^{\mathrm{lo}} \mathrm{CD} 16^{+}$as non-classical and $\mathrm{CD} 14^{+} \mathrm{CD} 16^{+}$as intermediate monocytes [44]. Moreover, some studies have been analyzed monocytes based on the expression of molecules related to differentiation/activation found in macrophages $[45,46]$. Despite several of these molecules were assessed in this study many others, such as CD68, CD163 and CD206 have been strongly correlated with different monocyte subsets [45].

As described here, both classical and inflammatory monocytes expressed the chemokine receptor CGR2. It was previously shown in the $P$. chabaudi rodent model of malaria that inflammatory monocytes migrate to spleens, in CGR2 dependent manner, where they are important effector cells implicated in the control of parasite burden, likely through their phagocytic activity and release of ROS [47]. CCR2, the chemokine receptor for CCL2 (also known as monocyte chemotactic protein-1) is a marker for inflammatory monocytes. These monocyte subsets were also shown to express higher levels of mRNA encoding CCL2 when compared to the patrolling monocytes. Similarly, a previous study reported that patients infected with either $P$. vivax or $P$. falciparum have high levels of circulating CGL2 [48]. Classical and inflammatory monocytes from $P$. vivax-infected patients also expressed high levels of inflammatory mediators, including CXCL2 and the receptors for TNF- $\alpha$, IFN- $\gamma$ and IL-1. Despite the similarities described above, $\mathrm{CD} 14^{+} \mathrm{CD} 16^{+}$monocytes displayed the highest frequencies of TNF- $\alpha$ producing cells when exposed to $\mathrm{Pv}$-Ret. Interestingly, $\mathrm{CD} 14^{+} \mathrm{CD} 16^{+}$monocytes also expressed higher mRNA for IL-10 than the other monocyte subsets. It has been described that highly activated effector cells can acquire regulatory features. During Leishmania [49,50], T. cruzi [51] and T. gondii [52] infection polarized Th1 cells produce IL-10 along to IFN- $\gamma$, in attempt to control immunopathology. The same has been described for monocytes. A recent article shows in the murine model of toxoplasmosis that $\mathrm{Ly}_{6 \mathrm{C}} \mathrm{C}^{\mathrm{h}}$ monocytes entering the gastrointestinal tract responded to commensal ligands by adopting a regulatory phenotype. For instance inflammatory monocytes became capable to control parasite burden while limiting collateral damage to tissue [53]. Indeed, plasma levels of IL-10 are lower with increased disease severity during $P$. vivax infection [42]. Thus, the expression of this counter regulatory cytokine may also represent an important role of $\mathrm{CD} 14^{+} \mathrm{CD} 16^{+}$monocytes in preventing immunopathology during $P$. vivax malaria.

Different adhesion molecules, including CD36, ICAM-1, VCAM-1 and PECAM-1 have been described as important receptors that bind $P$. falciparum infected red blood cells and influence the outcome of disease $[54,55]$. P. falciparum-infected erythrocytes are able to tether and roll on CD36, ICAM-1, Pselectin, and VCAM-1 in a shear-dependent fashion. In addition, CD36 has an important role in phagocytosis of $P$. falciparum infected cells $[56,57,58]$. On the other hand, ICAM-1, but not CD36, was implicated in the cythoadhesion of $P$. vivax to endothelium cells [22]. We found that $\mathrm{CD} 14^{+} \mathrm{CD} 16^{+} \mathrm{CCR} 2^{+}$ inflammatory monocytes from $P$. vivax malaria patients express the highest levels of ICAM-1, PECAM-1, and LFA-1. Although these adhesion molecules were originally identified as endothelium receptors for parasitized red blood cells, their expression on monocytes may favor biding and uptake of $P$. vivax infected reticulocytes. Indeed, our results indicate that the phagocytic activity of different monocyte subsets positively correlated with the expression of ICAM-1, PECAM-1 and LFA-1 and blockade of each of these adhesion molecules efficiently inhibited phagocytosis of Pv-Ret.

It is noteworthy that $\mathrm{CD} 14^{+} \mathrm{CD} 16^{+}$monocytes have also been reported to expand in a group of $P$. falciparum-infected patients, and total monocytes from these patients were able to better control parasite growth in vitro, through antibody dependent cellular inhibition [59,60]. CD16, a Fc $\gamma$ receptor, has a high affinity for IgGl and IgG3 [61] and therefore may be involved in phagocytosis of Plasmodium infected red blood cells. In contrast, experiments performed with Staphylococcus aureus or Echerichia coli showed that $\mathrm{CD} 14^{+}$monocytes have higher phagocytic activity than $\mathrm{CD} 14^{\text {lo }}$ monocytes. However no differences were observed between $\mathrm{CD} 14^{+} \mathrm{CD} 16^{+}$and $\mathrm{CD} 14^{+} \mathrm{CD} 16^{-}$monocytes [62]. In our system, the expression of CD16 was not the only molecule involved in phagocytosis since the ability of $\mathrm{Pv}$-Ret internalization was different between $\mathrm{CD}_{1} 4^{+}$and $\mathrm{CD} 14^{\text {lo }}$, both expressing CD16. The expression of adhesion molecules ICAM-1, PECAM-1 and LFA-1, though, appeared to play an important role in parasite internalization by inflammatory monocytes. In vitro studies have shown that hemozoin interferes in the upregulation of MHC class II and CD54 on monocytes after IFN- $\gamma$ stimulation [63], altering also their differentiation and maturation in dendritic cells [64] and antigen presentation [65]. Despite hemozoin is known to impair the ability of monocytes to repeat phagocytosis [66], no pigment was found when PBMC were evaluated in our study. Moreover, impairment in phagocytosis was not observed and the monocytes still produced ROS in response to PMA, in oppose to monocytes previously exposed to parasitized red blood cells [63]. We believe that phagocytosis of $P$. vivax-infected reticulocytes by monocytes are taking place in the spleen, where bona fide undifferentiated monocytes reside in equivalent numbers in circulation [67].

Besides their activated phenotype, CD $14^{+}$monocytes displayed an activated morphology with larger mitochondrias. Interestingly, the $\mathrm{CD} 14^{+} \mathrm{CD} 16^{+}$subset showed higher mitochondrial activity than the other monocyte subpopulations. Malaria infection triggers production of high levels of total ROS. Despite similar levels of total ROS are produced by different monocyte subsets, 
higher frequencies and levels of intracellular ROS, and higher expression of $\mathrm{p} 47 \mathrm{phox}$ and $\mathrm{p} 67$ phox were found in $\mathrm{CD} 14^{+} \mathrm{CD} 16^{+}$ cells compared to $\mathrm{CD} 14^{+} \mathrm{CD} 16^{-}$and $\mathrm{CD} 14^{\mathrm{lo}} \mathrm{CD} 16^{+}$monocytes. In addition, staining with MitoSox reveals that $\mathrm{CD} 14^{+} \mathrm{CD} 16^{+}$ monocytes produce higher levels of mitochondrial ROS. ROS are important effector free radicals involved in Plasmodium killing $[47,68]$. Indeed, either blockade of mitochondrial complex I or blockage of NADPH oxidases, both responsible for ROS generation, efficiently reduces ROS levels in PBMC and $\mathrm{CD} 14^{+} \mathrm{CD} 16^{+}$monocytes from malaria patients. Despite mitochondrial ROS have been regarded as byproducts of oxidative respiration, studies have indicated that mitochondria are recruited to vacuoles containing pathogens through an active process mediated by immune signaling [69,70,71]. Moreover, West and coworkers showed that the reduction of macrophage mitochondrial ROS results in defective bacterial killing [71].

Similarly to ROS production, higher frequencies of cells producing TNF- $\alpha$, a cytokine known to trigger the respiratory burst, were found among $\mathrm{CD} 14^{+} \mathrm{CD} 16^{+}$monocytes exposed to $\mathrm{Pv}$ Ret. In a different context, patients experiencing severe malarial anemia triggered by $P$. falciparum display increased numbers of circulating monocytes, with significant augment in the numbers of TNF- $\alpha$-producing CD $14^{+} \mathrm{CD} 16^{+}$monocytes [72]. It is still unclear what is the cause of anemia during malaria. Despite recent reports have shown evidence demonstrating that $P$. vivax malaria may be associated with higher frequency and more severe anemia than $P$. falciparum, most of these studies were performed with children already suffering from malnutrition and hospitalized subject $[73,74,75]$. Only a small proportion of the $P$. vivax-infected patients analyzed in this study presented mild anemia (Table S1) and their reticulocyte counts are according to the reference values [76]. In fact, $P$. vivax infection is responsible for very low frequencies of infected red blood cells. We believe that during uncomplicated vivax malaria, phagocytosis of reticulocytes by monocytes and the production of inflammatory mediators will preferentially help in the parasite control.

It is important to mention that $P$. vivax-infected patients display elevated levels of hepatic biomarkers such as aspartate (AST), alanine (ALT) aminotransferase and bilirubin. And despite no correlation was found between monocyte activation markers and most of the laboratory parameters, such as hematocrit and platelet counts, higher levels of AST correlated with higher expression of CCR2 and VCAM-1 on both $\mathrm{CD} 14^{+} \mathrm{CD} 16^{-}$and $\mathrm{CD} 14^{+} \mathrm{CD} 16^{+}$ monocytes and ICAM- 1 on CD $14^{+} \mathrm{CD}_{16}{ }^{-}$monocytes (Figure S3). These data indicate that in the attempt of controlling parasitemia, monocytes might cause inflammatory damage.

Finally, we observed that $\mathrm{CD} 14^{\mathrm{lo}} \mathrm{CD} 16^{+}$patrolling monocytes from $P$. vivax malaria patients did not express CGR2 but expressed high levels of LFA-1 and CX3CR1. The latter two receptors appear to be responsible for the ability of monocytes to patrol blood vessels in vivo [18]. Consistent with this hypothesis, $\mathrm{CD} 6^{+}$monocytes display enhanced capacity to adhere to endothelial cells in vitro. This ability is partially dependent on fractalkine, the CX3CR1 ligand and CD1 la, the $\alpha$ chain of LFA-1 [77]. Importantly, patrolling monocytes have been shown to express high levels of TLR8 and TLR9 [18], and may also play an important role on cytokine production in response to parasite RNA and DNA. Thus, patrolling monocytes may also contribute to the early inflammatory response observed during $P$. vivax infection.

In conclusion, our findings support the concept that highly activated monocytes are characteristic of acute malaria. $P$. vivaxinfection leads to cytokine production by classical and inflammatory monocytes, and this response is likely to be largely responsible for many of the signs and symptoms observed in malaria sepsis. Importantly, we demonstrate for the first time that $\mathrm{CD} 14^{+} \mathrm{CD} 16^{+}$ monocytes in malaria patients exhibited greater phagocytic activity and produced higher levels of intracellular TNF- $\alpha$ and reactive oxygen species, indicating their important role in parasite control and host resistance to infection. Further delineation of the differential roles of monocyte subsets in $P$. vivax malaria could lead to identification of specific targets for therapeutic intervention in this extremely important but highly neglected parasitic disease.

\section{Supporting Information}

Figure S1 Size and granularity of human monocyte subsets. Monocyte subsets are show in a forward scatter area (FSC-A) versus forward scatter height (FSC-H) dot plot. $\mathrm{CD} 14^{+} \mathrm{CD} 16^{-}$cells are shown in green, $\mathrm{CD} 14^{+} \mathrm{CD} 16^{+}$cells in red and $\mathrm{CD} 14^{\mathrm{l}} \mathrm{CD}_{16}{ }^{+}$in blue. Other cells from PBMC are shown in grey.

(EPS)

Figure S2 Apoptosis of monocyte subsets after phagocytosis. (A) Proportions of monocyte subsets and (B) frequencies of Annexin-V expressing $\mathrm{CD} 14^{+} \mathrm{CD} 16^{-}$(green symbols), $\mathrm{CD}_{14}{ }^{+} \mathrm{CD} 16^{+}$(red symbols) and $\mathrm{CD} 14^{\mathrm{l}} \mathrm{CD}^{+} 6^{+}$(blue symbols) monocytes in from $P$. vivax-infected patients. Cells were culture for 4 hours with $P$. vivax-infected reticulocytes (circles), 12 hours in medium alone (squares) or with $P$. vivax-infected reticulocytes (triangles). Symbols represent individual subject. $* p<0.05$.

(EPS)

Figure S3 Levels of aspartate aminotransferase (AST) correlate with immunological parameters expressed by monocytes from $P$. vivax-infected patients. (A) Levels of AST before (BT) and after (AT) treatment. Correlation between AST levels and CCR2, CD54, CD106 expression by $\mathrm{CD}_{14}^{+} \mathrm{CD} 16^{-}(\mathrm{B})$ or $\mathrm{CD} 14^{+} \mathrm{CD} 16^{+}(\mathrm{C})$ monocytes. The results are expressed as scattering of individual values. Circles indicate individual patients $(n=27)$. Spearman's rank correlation $(r)$ and $p$ values are shown in the graphs.

(EPS)

Figure S4 Production of reactive oxygen species during vivax malaria. Peripheral blood mononuclear cells and purified monocyte subsets from $P$. vivax-infected subjects were assessed for ROS production. (A) The kinetics of ROS production by PBMC from $P$. vivax-infected patients evaluated before $(\mathrm{BT})$ and after treatment (AT) when cells were cultured in medium alone (left panel) or PMA (right panel) in the presence of luminol measured by chemiluminescence using Synergy H4 (BioTek) microplate reader $(n=5)$. (B) The kinetics of ROS production by sorted $\mathrm{CD}_{14}^{+} \mathrm{CD} 16^{-}$(green circles), $\mathrm{CD} 14^{+} \mathrm{CD}^{+} 6^{+}$(red circles) and $\mathrm{CD} 14^{\mathrm{l}} \mathrm{CD}^{\circ} 6^{+}$(blue circles) from acutely $P$. vivax-infected patients cultured in medium alone (top panel), erythrocytes (RBC, middle panel) or $P$. vivax-infected reticulocytes ( $\mathrm{Pv}$-Ret, bottom panel) in the presence of carboxy- $\mathrm{H}_{2}$ DCFDA measured by fluorescence using SpectraMax M5 microplate reader $(n=4) .(C)$ The kinetics of ROS production by PBMC from acutely $P$. vivaxinfected patients cultured in medium alone (top panel) or PMA (bottom panel), in the presence of luminol, in the absence or in the presence of inhibitors of ROS production; rotenone and DPI. Bars represent mean values and standard error. Results were pooled from 4 independent experiments. Luminol was measured by chemiluminescence $(n=5)$. Statistical analysis were done comparing different treatments over time, $* * 0.05>p>0.01$. (D) Mean fluorescence intensity (MFI) of ROS production was assessed by flow cytometry in $\mathrm{CD} 14^{+} \mathrm{CD} 16^{+}$monocytes, among PBMC, from 
$P$. vivax-infected patients after culture with $P$. vivax-infected reticulocytes in the absence or in the presence of rotenone and DPI. Percentage of inhibition was calculated considering as 100\% the culture in the absence of inhibitors $(n=4)$. Symbols represent individual subject. Results are representative of 2 experiments. (EPS)

Table S1 Study population. Laboratory and clinical records of Plasmodium vivax-infected patients. (DOCX)

Text S1 Supporting methods for apoptosis assay and ROS detection.

(DOCX)

\section{References}

1. Gething PW, Elyazar IR, Moyes CL, Smith DL, Battle KE, et al. (2012) A long neglected world malaria map: Plasmodium vivax endemicity in 2010. PLoS Negl Trop Dis 6: e1814.

2. Langhorne J, Ndungu FM, Sponaas AM, Marsh K (2008) Immunity to malaria: more questions than answers. Nat Immunol 9: 725-732.

3. Spence PJ, Langhorne J (2012) T cell control of malaria pathogenesis. Curr Opin Immunol 24: 444-448.

4. Mueller I, Galinski MR, Baird JK, Carlton JM, Kochar DK, et al. (2009) Key gaps in the knowledge of Plasmodium vivax, a neglected human malaria parasite. Lancet Infect Dis 9: 555-566.

5. Leoratti FM, Trevelin SC, Cunha FQ, Rocha BC, Costa PA, et al. (2012) Neutrophil paralysis in Plasmodium vivax malaria. PLoS Negl Trop Dis 6: e1710.

6. Gazzinelli RT, Denkers EY (2006) Protozoan encounters with Toll-like receptor signalling pathways: implications for host parasitism. Nat Rev Immunol 6: 895906.

7. Takeuchi O, Akira S (2010) Pattern recognition receptors and inflammation. Cell 140: 805-820.

8. Franklin BS, Parroche P, Ataide MA, Lauw F, Ropert C, et al. (2009) Malaria primes the innate immune response due to interferon-gamma induced enhancement of toll-like receptor expression and function. Proc Natl Acad Sci U S A 106: 5789-5794.

9. Parroche P, Lauw FN, Goutagny N, Latz E, Monks BG, et al. (2007) Malaria hemozoin is immunologically inert but radically enhances innate responses by presenting malaria DNA to Toll-like receptor 9. Proc Natl Acad Sci U S A 104: 1919-1924.

10. Sharma S, DeOliveira RB, Kalantari P, Parroche P, Goutagny N, et al. (2011) Innate immune recognition of an AT-rich stem-loop DNA motif in the Plasmodium falciparum genome. Immunity 35: 194-207.

11. Kwiatkowski D, Hill AV, Sambou I, Twumasi P, Castracane J, et al. (1990) TNF concentration in fatal cerebral, non-fatal cerebral, and uncomplicated Plasmodium falciparum malaria. Lancet 336: 1201-1204.

12. McCall MB, Netea MG, Hermsen CG, Jansen T, Jacobs L, et al. (2007) Plasmodium falciparum infection causes proinflammatory priming of human TLR responses. J Immunol 179: 162-171.

13. Antonelli LR, Gigliotti Rothfuchs A, Goncalves R, Roffe E, Cheever AW, et al. (2010) Intranasal Poly-IC treatment exacerbates tuberculosis in mice through the pulmonary recruitment of a pathogen-permissive monocyte/macrophage population. J Clin Invest 120: 1674-1682.

14. Goncalves R, Zhang X, Cohen H, Debrabant A, Mosser DM (2011) Platelet activation attracts a subpopulation of effector monocytes to sites of Leishmania major infection. J Exp Med 208: 1253-1265.

15. Serbina NV, Cherny M, Shi C, Bleau SA, Collins NH, et al. (2009) Distinct responses of human monocyte subsets to Aspergillus fumigatus conidia. J Immunol 183: 2678-2687.

16. Passlick B, Flieger D, Ziegler-Heitbrock HW (1989) Identification and characterization of a novel monocyte subpopulation in human peripheral blood. Blood 74: 2527-2534.

17. Gordon S, Taylor PR (2005) Monocyte and macrophage heterogeneity. Nat Rev Immunol 5: 953-964.

18. Cros J, Cagnard N, Woollard K, Patey N, Zhang SY, et al. (2010) Human CD14dim monocytes patrol and sense nucleic acids and viruses via TLR7 and TLR8 receptors. Immunity 33: 375-386.

19. Zawada AM, Rogacev KS, Rotter B, Winter P, Marell RR, et al. (2011) SuperSAGE evidence for CD14++CD16+ monocytes as a third monocyte subset. Blood 118: e50-61.

20. Kaneko O, Kimura M, Kawamoto F, Ferreira MU, Tanabe K (1997) Plasmodium falciparum: allelic variation in the merozoite surface protein 1 gene in wild isolates from southern Vietnam. Exp Parasitol 86: 45-57.

21. Ihalamulla RL, Mendis KN (1987) Plasmodium vivax: isolation of mature asexual stages and gametocytes from infected human blood by colloidal silica (Percoll) gradient centrifugation. Trans R Soc Trop Med Hyg 81: 25-28.

\section{Acknowledgments}

We are grateful to Dr. Alan Sher, Dr. David Mosser and Dr. Kevin Maloy for critically reading this manuscript, to Dr. Luiz Hildebrando Pereira da Silva for supporting the development of this work in the endemic area of Porto Velho, to Dr. Maria Marta Figueiredo for technical support, to Dr. Nadja de Souza Pinto and Dr. Leda Quercia Vieira for reagents and to the nurses for excellent technical assistance.

\section{Author Contributions}

Conceived and designed the experiments: LRVA RG RTG. Performed the experiments: LRVA FMSL PACG BCR SQD RG ATC. Analyzed the data: LRVA FMSL BCR SQD RG MST DBP. Contributed reagents/ materials/analysis tools: LRVA DTG RG RTG. Wrote the paper: LRVA RTG.

22. Carvalho BO, Lopes SC, Nogueira PA, Orlandi PP, Bargieri DY, et al. (2010) On the cytoadhesion of Plasmodium vivax-infected erythrocytes. J Infect Dis 202: 638-647.

23. Chiarini-Garcia H, Hornick JR, Griswold MD, Russell LD (2001) Distribution of type A spermatogonia in the mouse is not random. Biol Reprod 65: 11791185.

24. Chiarini-Garcia H, Russell LD (2002) Characterization of mouse spermatogonia by transmission electron microscopy. Reproduction 123: 567-577.

25. Geiss GK, Bumgarner RE, Birditt B, Dahl T, Dowidar N, et al. (2008) Direct multiplexed measurement of gene expression with color-coded probe pairs. Nat Biotechnol 26: 317-325.

26. Dixit E, Boulant S, Zhang Y, Lee AS, Odendall C, et al. (2010) Peroxisomes are signaling platforms for antiviral innate immunity. Cell 141: 668-681.

27. Grip O, Bredberg A, Lindgren S, Henriksson G (2007) Increased subpopulations of CD16(+) and CD56(+) blood monocytes in patients with active Crohn's disease. Inflamm Bowel Dis 13: 566-572.

28. Auffray C, Fogg D, Garfa M, Elain G, Join-Lambert O, et al. (2007) Monitoring of blood vessels and tissues by a population of monocytes with patrolling behavior. Science 317: 666-670.

29. Lambeth JD (2004) Nox enzymes and the biology of reactive oxygen. Nature Reviews Immunology 4: 181-189.

30. Balaban RS, Nemoto S, Finkel T (2005) Mitochondria, oxidants, and aging. Cell 120: 483-495.

31. Chance B, Sies H, Boveris A (1979) Hydroperoxide metabolism in mammalian organs. Physiol Rev 59: 527-605.

32. Balaban RS, Nemoto S, Finkel T (2005) Mitochondria, oxidants, and aging. Cell 120: 483-495.

33. Highton J, Carlisle B, Palmer DG (1995) Changes in the phenotype of monocytes/macrophages and expression of cytokine mRNA in peripheral blood and synovial fluid of patients with rheumatoid arthritis. Clin Exp Immunol 102: 541-546.

34. Phillips RJ, Lutz M, Premack B (2005) Differential signaling mechanisms regulate expression of $\mathrm{CG}$ chemokine receptor-2 during monocyte maturation. J Inflamm (Lond) 2: 14.

35. Trial J, Birdsall HH, Hallum JA, Crane ML, Rodriguez-Barradas MC, et al. (1995) Phenotypic and functional changes in peripheral blood monocytes during progression of human immunodeficiency virus infection. Effects of soluble immune complexes, cytokines, subcellular particulates from apoptotic cells, and HIV-1-encoded proteins on monocytes phagocytic function, oxidative burst, transendothelial migration, and cell surface phenotype. J Clin Invest 95: 16901701.

36. Turrini F, Ginsburg H, Bussolino F, Pescarmona GP, Serra MV, et al. (1992) Phagocytosis of Plasmodium-Falciparum-Infected Human Red-Blood-Cells by Human Monocytes - Involvement of Immune and Nonimmune Determinants and Dependence on Parasite Developmental Stage. Blood 80: 801-808.

37. Bulua AC, Simon A, Maddipati R, Pelletier M, Park H, et al. (2011) Mitochondrial reactive oxygen species promote production of proinflammatory cytokines and are elevated in TNFR1-associated periodic syndrome (TRAPS). Journal of Experimental Medicine 208: 519-533.

38. Hancock JT, Jones OTG (1987) The Inhibition by Diphenyleneiodonium and Its Analogs of Superoxide Generation by Macrophages. Biochemical Journal 242: $103-107$

39. Stuehr DJ, Fasehun OA, Kwon NS, Gross SS, Gonzalez JA, et al. (1991) Inhibition of Macrophage and Endothelial-Cell Nitric-Oxide Synthase by Diphenyleneiodonium and Its Analogs. Faseb Journal 5: 98-103.

40. Othoro C, Lal AA, Nahlen B, Koech D, Orago AS, et al. (1999) A low interleukin-10 tumor necrosis factor-alpha ratio is associated with malaria anemia in children residing in a holoendemic malaria region in western Kenya. J Infect Dis 179: 279-282.

41. Kurtzhals JA, Adabayeri V, Goka BQ, Akanmori BD, Oliver-CommeyJO, et al. (1998) Low plasma concentrations of interleukin 10 in severe malarial anaemia compared with cerebral and uncomplicated malaria. Lancet 351: 1768-1772. 
42. Andrade BB, Reis-Filho A, Souza-Neto SM, Clarencio J, Camargo LM, et al. (2010) Severe Plasmodium vivax malaria exhibits marked inflammatory imbalance. Malar J 9: 13.

43. Skorokhod OA, Alessio M, Mordmuller B, Arese P, Schwarzer E (2004) Hemozoin (malarial pigment) inhibits differentiation and maturation of human monocyte-derived dendritic cells: a peroxisome proliferator-activated receptorgamma-mediated effect. J Immunol 173: 4066-4074.

44. Ziegler-Heitbrock L, Ancuta P, Crowe S, Dalod M, Grau V, et al. (2010) Nomenclature of monocytes and dendritic cells in blood. Blood 116: e74-80.

45. Fadini GP, Cappellari R, Mazzucato M, Agostini C, Vigili de Kreutzenberg S, et al. (2013) Monocyte-macrophage polarization balance in pre-diabetic individuals. Acta Diabetol 50: 977-982.

46. Mantovani A, Garlanda C, Locati M (2009) Macrophage diversity and polarization in atherosclerosis: a question of balance. Arterioscler Thromb Vasc Biol 29: 1419-1423.

47. Sponaas AM, Freitas do Rosario AP, Voisine C, Mastelic B, Thompson J, et al. (2009) Migrating monocytes recruited to the spleen play an important role in control of blood stage malaria. Blood 114: 5522-5531.

48. Fernandes AA, Carvalho LJ, Zanini GM, Ventura AM, Souza JM, et al. (2008) Similar cytokine responses and degrees of anemia in patients with Plasmodium falciparum and Plasmodium vivax infections in the Brazilian Amazon region. Clin Vaccine Immunol 15: 650-658.

49. Nylen S, Maurya R, Eidsmo L, Das Manandhar K, Sundar S, et al. (2007) Splenic accumulation of IL-10 mRNA in T cells distinct from CD4(+) CD25(+) (Foxp3) regulatory $\mathrm{T}$ cells in human visceral leishmaniasis. Journal of Experimental Medicine 204: 805-817.

50. Anderson CF, Oukka M, Kuchroo VJ, Sacks D (2007) CD4(+)CD25(Foxp3(-) Th1 cells are the source of IL-10-mediated immune suppression in chronic cutaneous leishmaniasis. Journal of Experimental Medicine 204: 285297.

51. Roffe E, Rothfuchs AG, Santiago HC, Marino APMP, Ribeiro-Gomes FL, et al. (2012) IL-10 Limits Parasite Burden and Protects against Fatal Myocarditis in a Mouse Model of Trypanosoma cruzi Infection. Journal of Immunology 188: 649-660.

52. Jankovic D, Kullberg MC, Feng CG, Goldszmid RS, Collazo CM, et al. (2007) Conventional T-bet(+)Foxp3(-) Th1 cells are the major source of hostprotective regulatory IL-10 during intracellular protozoan infection. Journal of Experimental Medicine 204: 273-283.

53. Grainger JR, Wohlfert EA, Fuss IJ, Bouladoux N, Askenase MH, et al. (2013) Inflammatory monocytes regulate pathologic responses to commensals during acute gastrointestinal infection. Nature Medicine 19: 713-+.

54. Newbold C, Warn P, Black G, Berendt A, Craig A, et al. (1997) Receptorspecific adhesion and clinical disease in Plasmodium falciparum. Am J Trop Med Hyg 57: 389-398.

55. Rowe JA, Claessens A, Corrigan RA, Arman M (2009) Adhesion of Plasmodium falciparum-infected erythrocytes to human cells: molecular mechanisms and therapeutic implications. Expert Rev Mol Med 11: e16.

56. Udomsangpetch R, Reinhardt PH, Schollaardt T, Elliott JF, Kubes P, et al. (1997) Promiscuity of clinical Plasmodium falciparum isolates for multiple adhesion molecules under flow conditions. J Immunol 158: 4358-4364.

57. Ayi K, Patel SN, Serghides L, Smith TG, Kain KC (2005) Nonopsonic phagocytosis of erythrocytes infected with ring-stage Plasmodium falciparum. Infect Immun 73: 2559-2563.

58. McGilvray ID, Serghides L, Kapus A, Rotstein OD, Kain KC (2000) Nonopsonic monocyte/macrophage phagocytosis of Plasmodium falciparumparasitized erythrocytes: a role for CD36 in malarial clearance. Blood 96: 32313240 .

59. Chimma P, Roussilhon C, Sratongno P, Ruangveerayuth R, Pattanapanyasat K, et al. (2009) A distinct peripheral blood monocyte phenotype is associated with parasite inhibitory activity in acute uncomplicated Plasmodium falciparum malaria. PLoS Pathog 5: e1000631.

60. Jaworowski A, Kamwendo DD, Ellery P, Sonza S, Mwapasa V, et al. (2007) CD16+ monocyte subset preferentially harbors HIV-1 and is expanded in pregnant Malawian women with Plasmodium falciparum malaria and HIV-1 infection. J Infect Dis 196: 38-42.

61. Nimmerjahn F, Ravetch JV (2011) FcgammaRs in health and disease. Curr Top Microbiol Immunol 350: 105-125.

62. Skrzeczynska-Moncznik J, Bzowska M, Loseke S, Grage-Griebenow E, Zembala M, et al. (2008) Peripheral blood CD14high CD16+ monocytes are main producers of IL-10. Scand J Immunol 67: 152-159.

63. Schwarzer E, Turrini F, Ulliers D, Giribaldi G, Ginsburg H, et al. (1992 Impairment of macrophage functions after ingestion of Plasmodium falciparuminfected erythrocytes or isolated malarial pigment. Journal of Experimental Medicine 176: 1033-1041.

64. Skorokhod OA, Alessio M, Mordmuller B, Arese P, Schwarzer E (2004) Hemozoin (malarial pigment) inhibits differentiation and maturation of human monocyte-derived dendritic cells: a peroxisome proliferator-activated receptorgamma-mediated effect. Journal of Immunology 173: 4066-4074.

65. Scorza T, Magez S, Brys L, De Baetselier P (1999) Hemozoin is a key factor in the induction of malaria-associated immunosuppression. Parasite Immunol 21: $545-554$.

66. Schwarzer E, Alessio M, Ulliers D, Arese P (1998) Phagocytosis of the malarial pigment, hemozoin, impairs expression of major histocompatibility complex class II antigen, CD54, and CD11c in human monocytes. Infect Immun 66: $1601-1606$

67. Swirski FK, Nahrendorf M, Etzrodt M, Wildgruber M, Cortez-Retamozo V, et al. (2009) Identification of splenic reservoir monocytes and their deployment to inflammatory sites. Science 325: 612-616.

68. Kumar S, Christophides GK, Cantera R, Charles B, Han YS, et al. (2003) The role of reactive oxygen species on Plasmodium melanotic encapsulation in Anopheles gambiae. Proc Natl Acad Sci U S A 100: 14139-14144.

69. Matsumoto A, Bessho H, Uehira K, Suda T (1991) Morphological studies of the association of mitochondria with chlamydial inclusions and the fusion of chlamydial inclusions. J Electron Microsc (Tokyo) 40: 356-363.

70. Sinai AP, Webster P, Joiner KA (1997) Association of host cell endoplasmic reticulum and mitochondria with the Toxoplasma gondii parasitophorous vacuole membrane: a high affinity interaction. J Cell Sci 110 (Pt 17): 2117-2128.

71. West AP, Brodsky IE, Rahner C, Woo DK, Erdjument-Bromage H, et al. (2011) TLR signalling augments macrophage bactericidal activity through mitochondrial ROS. Nature 472: 476-480.

72. Ogonda LA, Orago AS, Otieno MF, Adhiambo C, Otieno W, et al. (2010) The levels of $\mathrm{CD} 16 / \mathrm{Fc}$ gamma receptor IIIA on CD14+ CD16+ monocytes are higher in children with severe Plasmodium falciparum anemia than in children with cerebral or uncomplicated malaria. Infect Immun 78: 2173-2181.

73. Alexandre MA, Ferreira CO, Siqueira AM, Magalhaes BL, Mourao MP, et al (2010) Severe Plasmodium vivax malaria, Brazilian Amazon. Emerg Infect Dis 16: $1611-1614$.

74. Douglas NM, Anstey NM, Buffet PA, Poespoprodjo JR, Yeo TW, et al. (2012) The anaemia of Plasmodium vivax malaria. Malar J 11: 135.

75. Rodriguez-Morales AJ, Sanchez E, Vargas M, Piccolo C, Colina R, et al. (2006) Anemia and thrombocytopenia in children with Plasmodium vivax malaria. J Trop Pediatr 52: 49-51.

76. Lewis SM, Bain BJ, Bates I (2006) Dacie and Lewis Practical Haematology. Philadelphia: Churchill Livingstone Elsevier. 736 p.

77. Ancuta P, Rao R, Moses A, Mehle A, Shaw SK, et al. (2003) Fractalkine preferentially mediates arrest and migration of CD16+ monocytes. J Exp Med 197: 1701-1707. 